Research Article

\title{
Investigation of the Effects of Freeze-Thaw Cycles on Geomechanical and Acoustic Characteristics of Tuff Specimens under Different Stress Paths
}

\author{
Yong-gang Xiao, ${ }^{1,2,3}$ Chang-hong Li $\mathbb{C D}^{1,2}$ Jie Cao ${ }^{1}{ }^{3}{ }^{3}$ Yu Wang, ${ }^{1,2}$ Zhi-qiang Hou, ${ }^{1,2}$ \\ and Nan $H \mathbf{u}^{1,2}$ \\ ${ }^{1}$ Key Laboratory of Ministry of Education for High-Efficient Mining and Safety of Metal Mines, \\ University of Science and Technology Beijing, Beijing 100083, China \\ ${ }^{2}$ School of Civil and Resource Engineering, University of Science and Technology Beijing, Beijing 100083, China \\ ${ }^{3}$ Department of Architecture and Civil Engineering, Chengde Petroleum College, Chengde 067000, China
}

Correspondence should be addressed to Chang-hong Li; lch@ustb.edu.cn and Jie Cao; caojieshiyou@163.com

Received 23 October 2020; Revised 1 December 2020; Accepted 8 December 2020; Published 22 December 2020

Academic Editor: Zhijie Wen

Copyright (c) 2020 Yong-gang Xiao et al. This is an open access article distributed under the Creative Commons Attribution License, which permits unrestricted use, distribution, and reproduction in any medium, provided the original work is properly cited.

\begin{abstract}
In the process of development and construction of open-pit mine slope in the high altitude and cold area, freeze-thaw (F-T) cycles have an important impact on rock engineering structure. F-T cycles lead to the decrease in physical and mechanical properties of rock, which is closely related to the stability of open-pit slope. In this paper, the influence of F-T cycles on geomechanical and acoustic emission (AE) characteristics of tuff specimens under different stress paths was studied by using F-T cycle treatment, in situ AE monitoring, and uniaxial loading test. The results indicated that under the same stress path, the cumulative AE count/ energy of rock samples subjected to F-T cycles was less than that of rock samples not subjected to F-T cycles. The peak frequency distribution of AE signal during the loading process of rock specimen presented the phenomenon of frequency bands. The width of the low-frequency band of the rock samples subjected to F-T cycles was larger than that of the rock samples under the natural state. The frequency and width of the high-frequency band of the rock samples subjected to F-Tcycles were larger than those of the rock samples under the natural state. The rock samples subjected to F-T cycles had higher plastic strain than those without F-T cycles. According to the uniaxial compression test results of F-T rock samples under different stress paths, the peak stress and peak strain have little change, but the AE characteristics were obviously different.
\end{abstract}

\section{Introduction}

In recent years, with the depletion of mineral resources in low altitude areas, the development and utilization of metal mineral resources in high altitude and cold areas have become the focus of China. In the process of mine development and construction, especially in the freezing and thawing environment, environmental geological disasters occur frequently. When water turns into ice in a cold environment, 9\% volume expansion will increase the pressure in pores and microcracks $[1,2]$. Frost heaving pressure drives the microcracks to propagate and produce new microcracks. The original microcracks widen with the deepening of microcracks, forming various rock mesostructures and corresponding mechanical properties. Freeze-thaw cycles lead to the decrease in physical and mechanical properties of rock, which is closely related to the stability of open-pit slope [3]. In order to ensure the safety and stability of mine slope engineering after F-T cycles, it is of great practical and theoretical significance to study the damage and deterioration characteristics of rock under F-T cycles. 
The deterioration of mechanical properties of rocks under F-T cycles has been widely studied. Related scholars have made a lot of research on the mechanical properties of rocks under the action of F-T cycles. Bost and Pouya [4] and Seto [5] conducted in situ monitoring to reveal the damage and deterioration characteristics of rocks during $\mathrm{F}-\mathrm{T}$ action during the continuous freezing period. Bayram [6] studied the changes of uniaxial strength, impact strength, tensile strength, elastic modulus, and bending strength of rocks under repeated F-T treatment and proposed a method to predict the mechanical strength loss of natural stone after F-T. Jamshidi et al. [7] predicted the long-term strength of rocks after F-T treatment and proposed a strength attenuation model. Park et al. [8] studied the changes of internal microstructure of diorite, basalt, and tuff during F-T cycles by X-ray computed tomography (CT) and the scanning electron microscope (SEM). Chen et al. [9] studied the effect of F-T cycles on the damage and deterioration of fused tuff samples with different saturation. Ke et al. [10] studied the reduction of static strength and dynamic strength of sandstone under different F-T cycles and proposed the attenuation model of rock dynamic strength. Zhao et al. [11] studied the damage and deterioration characteristics of oil shale uniaxial compressive strength and microcracks under F-T cycles. Ince and Fener [12] conducted F-T cycle tests on 10 pyroclastic rock samples from Cappadocia and established a statistical model of strength loss percentage to predict the uniaxial compressive strength loss percentage of pyroclastic rocks, which has high reliability. Jia et al. [13] compared the frost heaving deformation and uniaxial tensile deformation of sandstone samples with different saturations, which not only shows that the frost heaving deformation of sandstone is related to saturation but also proves that the maximum frost heaving deformation beyond a certain saturation will have irreversible residual deformation. Han et al. [14] studied the damage mechanism of sandstone samples under the coupling effect of different chemical solutions and fast F-T cycles, and the results showed that the fracture toughness and strength of sandstone samples deteriorated to varying degrees with the increase in F-T cycles. Chen et al. [15] carried out the F-T cycle test on soft rock material specimen and established the calculation model of F-T slope stability. The results show that water content and number of F-T cycles have significant influence on mechanical parameters of soft rock. Luo et al. [16] collected diabase rocks from an iron mine slope in a cold region and compared the F-T coefficient $\left(K_{f}\right)$ and rock strength loss rate $\left(R_{\sigma}\right)$ of diabase rock samples and metamorphic diabase rock samples so as to study the F-T damage deterioration law of the two rock samples. Ghobadi and Babazadeh [17] conducted $60 \mathrm{~F}-\mathrm{T}$ cycle tests on sandstone samples from a certain area in western Iran. The results show that there are great differences in rock weathering characteristics of the same stratum, and the dry and wet conditions have a great influence on the sandstone characteristics. Fang et al. [18] pointed out that with the decrease in the minimum temperature and $\mathrm{pH}$ value of corrosion solution, the compressive strength and elastic modulus of yellow sandstone decrease, which indicates that the bearing capacity and deformation resistance decrease with the increase in ductility. De Kock et al. [19] discussed the possibility of micro CT technology in studying the dynamic change of pore size during F-T process. The test showed that when the porous limestone is cooled to $-9.7^{\circ} \mathrm{C}$, the fracture network develops, at this time, ice crystallizes and releases latent heat, and the water absorption path and rock texture structure affect the location of cracks. Wang et al. [20-22] studied the effect of F-T cycles on fracture propagation and deformation of granite with rock bridge structure by AE monitoring technology and CT scanning technology. Zhou et al. [23] studied the relationship between mesostructural damage and dynamic characteristics of sandstone and the relationship between meso F-T damage and macromechanical strength of granite using nuclear magnetic resonance technology (NMR); Zhai et al. [24] studied the influence of F-T on pore structure degradation of coal samples and coal seam permeability by NMR and SEM. Ni et al. [25] tested the damage characteristics of tunnel sandstone samples in the cold region by the triaxial unloading test and $\mathrm{AE}$ technology. Chen et al. [26] studied the influence of F-T on the mechanical properties of rock under compression shear combined load through SEM, AE, and compression shear test system. Liu et al. [27] used the triaxial seepage test and AE monitoring method to study the mechanical and hydraulic characteristics of argillaceous sandstone under a full F-T cycles. Amitrano et al. [28] used AE monitoring technology to study the damage of alpine rock wall under natural thermal cycles and F-T action. Yin et al. [29] studied the effect of cyclic heating and cooling treatment on the characteristics of mode I fracture of granite by AE, SEM, and fracture tests. Liu et al. [30] studied the development of microcracks in red sandstone under cyclic heating and cooling through AE and SEM techniques.

To sum up, the damage and mechanical behavior of rock after F-T treatment have been widely studied by means of AE, SEM, CT scanning, and NMR. However, most of the rock samples were sandstone, granite, and other lithology, and there was little research on the F-T characteristics of tuff. In addition to F-T cycles, the slope rock mass of Alpine mine is also affected by heavy vehicles, frequent blasting, continuous excavation, and other loads. There are insufficient studies on the damage mechanism of rock under different stress paths. In this paper, we aimed to characterize and understand the damage behavior of slope tuff in cold regions. The change of AE signal can reflect the fracture process during uniaxial compression. In the laboratory, the artificial weathering simulator was used to simulate the physical weathering caused by water freezing and thawing in rock. In this study, real-time AE monitoring of tuff samples under different stress paths was mainly carried out. The fracture evolution and AE characteristics of rock in the whole deformation process were studied in detail. It is of great engineering value and safety significance for high cold and open-pit slopes such as Beizhan iron mine in Hejing county that the mechanical and 
acoustic characteristics of freeze-thaw tuff are studied under different stress paths.

\section{Materials and Test Method}

2.1. Rock Material and Sample Preparation. The rock materials used in the test were collected from the open-pit slope of Beizhan iron mine in Hejing County, Xinjiang, Northwest China. The rock lithology was tuff, which was distributed on the east side slope of the open-pit mine, as shown in Figure 1. The specific mountain height of the mining area was $700 \sim 1000 \mathrm{~m}$, the general terrain slope was $25 \sim 35^{\circ}$, and the gully was deep and steep, which belonged to the deep mountain landform. The altitude of the ore body was $3450-3723 \mathrm{~m}$. Several hundred meters to the south of the mining area was the Tianshan mountain ridge, which was covered by glaciers all the year round and had typical glacial geomorphic features. Modern glaciers, ice erosion depressions, glacial U-shaped valleys, and glacial cliffs were relatively developed. Beizhan iron mine belonged to the high altitude and cold mining area, which was located in the cold climate area with snow all the year round. The monthly average temperature from January to April and September to December over the years was below zero, and the lowest temperature can reach $-40^{\circ} \mathrm{C}$; the temperature rised from May to August, with the highest temperature about $20^{\circ} \mathrm{C}$, generally $5-15^{\circ} \mathrm{C}$; in summer, the night temperature was generally $-3 \sim-5^{\circ} \mathrm{C}$, and the temperature difference between day and night was large. With the change of temperature, the rock slope will have repeated F-T cycles.

All the specimens were drilled from the same complete tuff. The large rocks were separated by the method of splitting and separating with drilling expansion agent and then fixed and transported to the laboratory by using a wooden box. According to ISRM (International Society for Rock Mechanics and Rock Engineering), the tuff specimens were processed into standard cylindrical specimens with a height of $100 \mathrm{~mm}$ and a diameter of $50 \mathrm{~mm}$. Both ends of the sample are polished to ensure that the nonuniformity error was less than $0.05 \mathrm{~mm}$, and the parallelism of both ends was less than $0.1 \mathrm{~mm}$.

2.2. F-T Cycle Test. Before the rock mechanical test, the specimens were treated with F-T. The Js-dw- 40 cryocooler (as shown in Figure 2(a)) was used to realize F-T cycles. Combined with the actual situation of Hejing Beizhan openpit slope, the freezing temperature is $-40^{\circ} \mathrm{C}$, the freezing time is $8 \mathrm{~h}$, the melting temperature is $20^{\circ} \mathrm{C}$, the melting time is $8 \mathrm{~h}$, and the freezing and thawing times are 30 (as shown in Figure 2(b)). After the rock sample is processed, the test is carried out according to the following steps:

(1) The density and P-wave velocity of tuff specimens under natural conditions were measured. All the samples were put in the oven, dried at $110^{\circ} \mathrm{C}$ for $24 \mathrm{~h}$, cooled to room temperature in a drying dish, and weighed and recorded the dry mass $m_{s}$.

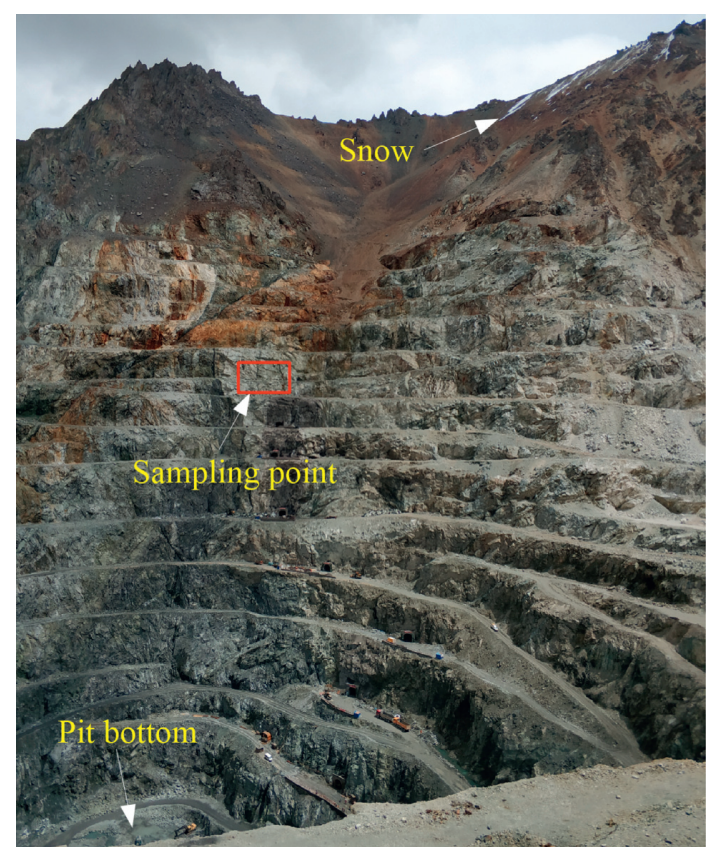

FIgURE 1: Rock samples were collected from the eastern slope of Beizhan Iron Mine.

(2) The sample was saturated by air extraction (soak the samples for $48 \mathrm{~h}$ after the completion of air extraction to make it fully saturated).

(3) The rock sample was always submerged in the water surface, and then the rock sample was taken out after full saturation, and the mass $m_{p}$ of saturated specimen before freezing and thawing was measured in a low temperature box with an ambient temperature of $40^{\circ} \mathrm{C}$, and they were frozen for 8 hours.

(4) After freezing, the rock samples were taken out and thawed in pure water at $20^{\circ} \mathrm{C}$ for $8 \mathrm{~h}$, and the rock samples were always submerged in the water surface.

(5) After the F-T cycles, the specimens were taken out of the water, and the surfaces moisture were wiped dry. Then, the mass $m_{f m}$ was weighed, and the longitudinal wave velocity $v_{f m}$ was measured. Check the F-T damage of each sample, whether there is falling block, cracking, and other phenomena, and record the F-T damage process of each sample.

(6) Steps (3)-(4) were a F-T cycles process. Every 10 F-T cycles was a period. After a period, step (5) was carried out, and then the corresponding mechanical tests of two groups of rock samples were conducted.

(7) After the F-T cycle test, the rock samples were subjected to the uniaxial test until they were completely destroyed.

Tuff was a kind of pyroclastic rock. The tuff used in this study was loose, porous, and rough. It was mainly gray white. The crystal pyroclast was composed of quartz, feldspar, and a small amount of dark minerals. They had tuff structure and massive structure. The tuff specimens were divided into two groups according to whether they were F-T 


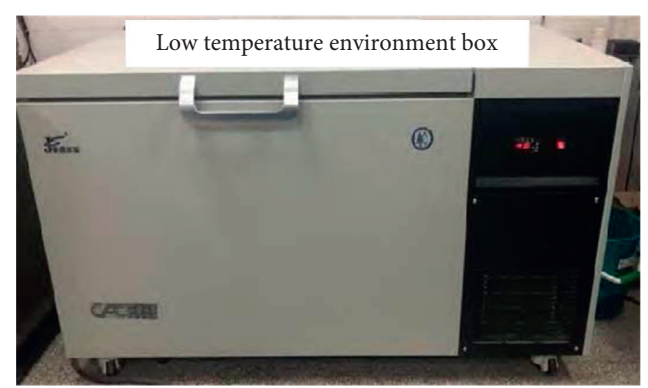

(a)

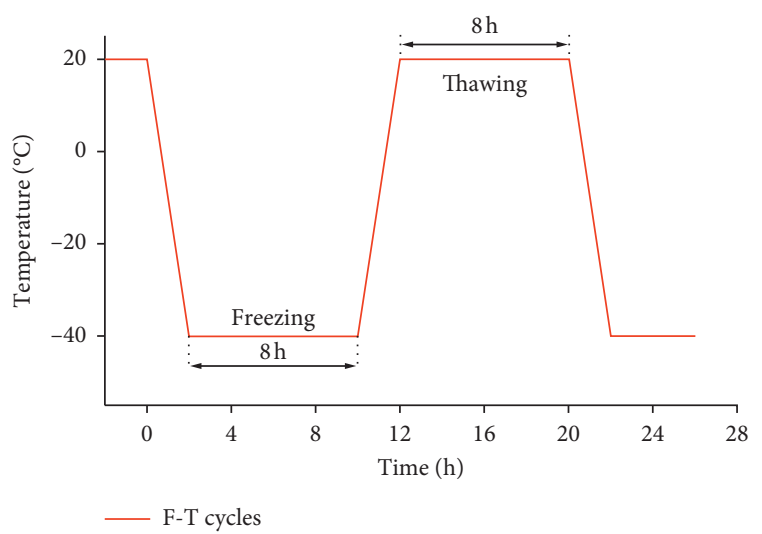

(b)

Figure 2: F-T treatment of specimens before the uniaxial compression test: (a) low temperature F-T environment box; (b) the temperature diagram of F-T.

treated or not. The first group was unfrozen rock samples, which were recorded as NF1, NF2, NF3, and NF4, respectively; the second group was F-T rock samples, which were recorded as FT1, FT2, FT3, and FT4. The F-T cycles of FT1-1 and FT1-2 were 10 and 20 times, respectively, and the F-T cycles of other specimens were 30 . The specimens are shown in Table 1.

2.3. Uniaxial Loading Test and AE Monitoring. In order to study the deterioration characteristics of rock structure under mining conditions in alpine slope, uniaxial loading tests were carried out on frozen and thawed rock samples. Open-pit mining often causes periodic disturbance to slope rock mass [31-34]. The essence of rock slope excavation is unloading process of rock mass [35-37]. Therefore, four kinds of uniaxial compression test schemes of stress paths were designed. Four stress paths were used for loading. The first was conventional uniaxial monotonic loading with deformation control at a loading rate of $0.02 \mathrm{~mm} / \mathrm{min}$ until the specimen fails, as shown in Figure 3(a), marked as condition 1 . The second stress path was cyclic loading with the stress amplitude of $15 \mathrm{MPa}$. The average stress of the first cycle loading stage was $15 \mathrm{MPa}$, and the number of cycles was 30 . The average stress increased by $15 \mathrm{MPa}$ in each cycle after loading, and the number of cycles was 30. The loading control method was axial constant velocity stress control $(200 \mathrm{~N} / \mathrm{s})$. This cyclic loading was continued until the rock sample fails, as shown in Figure 3(b), marked as condition 2. The third stress path was similar to the second one, which was cyclic loading with the stress amplitude of $10 \mathrm{MPa}$. Other loading methods were the same as the second one, marked as condition 3. The fourth stress path was equal increment cyclic loading; that was, the maximum value of loading in a single cycle increased by an equal amount compared with the previous cycle. The loading control mode was axial constant velocity stress control $(200 \mathrm{~N} / \mathrm{s})$. In addition, the axial deformation and radial deformation were measured in the whole process. The initial unloading point was $20 \mathrm{MPa}$, the unloading end point was $10 \mathrm{MPa}$, and the incremental load was $15 \mathrm{MPa}$. Such incremental cyclic loading was carried out until the rock sample fails as shown in Figure 3(c) and marked as condition 4.

All the mechanical tests were carried out on the servo controlled uniaxial rigid pressure test system (GAW-2000), as shown in Figure 4(a). During each test, one radial sensor and two axial sensors of the LVDT system were used to monitor the axial and lateral strain simultaneously, and the strength and deformation information of rock samples were recorded by a central computer, as shown in Figure 4(b). The $\mathrm{AE}$ instrument used in this test is PCI-2 AE instrument produced by American physical acoustics company (PAC), as shown in Figure 4(c). The selected AE sensor was the R6 $\alpha$ resonant high-sensitivity sensor. The preamplifier gain was $40 \mathrm{~dB}$, the sampling frequency was $1 \mathrm{MSPS}$, and the threshold value was $40 \mathrm{~dB}$. The AE system was used to record the number of AE events, energy, and frequency of characteristic signals in the process of rock sample fracture so as to monitor the crack initiation, propagation, and coalescence behavior.

\section{Test Results and Analysis}

3.1. F-T Damage of Rocks. In this paper, the F-T fatigue damage of rock was analyzed from mass loss rate $(M)$, F-T coefficient $\left(K_{f m}\right)$, and P-wave velocity loss rate $(P)$. The mass loss rate of rock sample was the ratio of the difference between the mass of specimen before and after F-T and the mass of dried specimen before the test; the F-T coefficient was the ratio of uniaxial compressive strength of rock after F-T to saturated uniaxial compressive strength of rock; the loss rate of $\mathrm{P}$-wave velocity was the ratio of the difference of 
TABLE 1: Grouping and basic physical and mechanical parameters of the tuff used in this test.

\begin{tabular}{|c|c|c|c|c|c|c|c|}
\hline Testing group & Sample ID & $L \times D(\mathrm{~mm} \times \mathrm{mm})$ & $m_{s}(\mathrm{~g})$ & $m_{p}(\mathrm{~g})$ & P-wave velocity $(\mathrm{m} / \mathrm{s})$ & Number of F-T cycles & Loading conditions \\
\hline \multirow{4}{*}{ I } & NF1 & $99.12 \times 49.62$ & 447.06 & 457.18 & 3774 & 0 & Condition 1 \\
\hline & NF2 & $99.28 \times 49.48$ & 452.20 & 462.95 & 3623 & 0 & Condition 2 \\
\hline & NF3 & $99.36 \times 49.32$ & 452.92 & 460.21 & 3802 & 0 & Condition 3 \\
\hline & NF4 & $100.23 \times 49.73$ & 456.23 & 465.93 & 3425 & 0 & Condition 4 \\
\hline \multirow{6}{*}{ II } & FT1-1 & $99.75 \times 48.92$ & 452.36 & 459.61 & 3745 & 10 & Condition 1 \\
\hline & FT1-2 & $99.64 \times 49.58$ & 453.24 & 461.37 & 3787 & 20 & Condition 1 \\
\hline & FT1-3 & $99.83 \times 49.65$ & 450.89 & 458.86 & 3653 & 30 & Condition 1 \\
\hline & FT2 & $98.78 \times 49.28$ & 444.20 & 452.92 & 3745 & 30 & Condition 2 \\
\hline & FT3 & $100.31 \times 49.79$ & 453.76 & 464.24 & 4049 & 30 & Condition 3 \\
\hline & FT4 & $99.92 \times 49.28$ & 455.13 & 464.13 & 3597 & 30 & Condition 4 \\
\hline
\end{tabular}

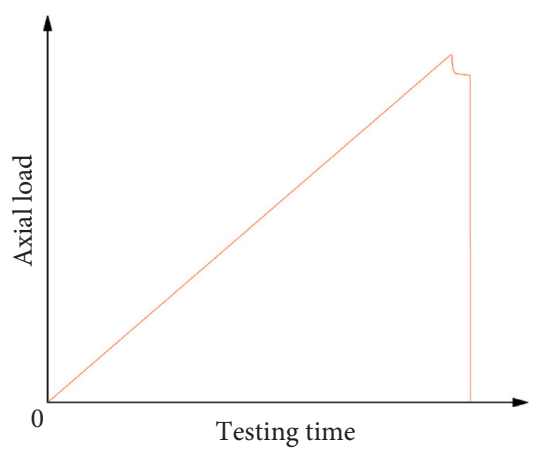

(a)

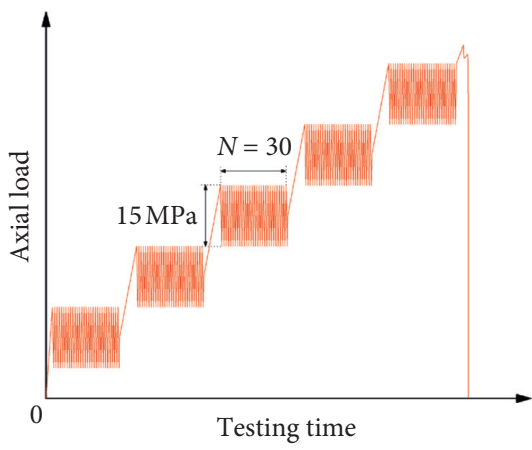

(b)

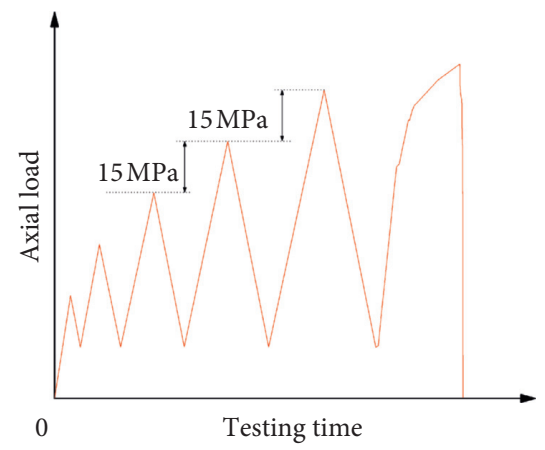

(c)

Figure 3: Three different stress paths: (a) conventional uniaxial compression tests; (b) increasing amplitude stress-cycling tests; (c) equal incremental cyclic loading tests.

P-wave velocity of specimen before and after F-T to that of dried specimen before the test. These parameters were expressed in percentages, and their expressions are as follows:

$$
\begin{aligned}
M & =\frac{m_{p}-m_{f m}}{m_{s}} \times 100 \%, \\
K_{f m} & =\frac{\bar{R}_{f m}}{\bar{R}_{w}} \times 100 \%, \\
P & =\frac{v_{p}-v_{f m}}{v_{s}} \times 100 \%,
\end{aligned}
$$

where $m_{p}$ denotes the mass of saturated specimen before F-T; $m_{f m}$ denotes mass of specimen after F-T; $m_{s}$ denotes mass of dried specimen before the test; $\bar{R}_{f m}$ denotes average uniaxial compressive strength of rock after F-T; $\bar{R}_{w}$ denotes average saturated uniaxial compressive strength of rock; $v_{p}$ denotes saturated P-wave velocity before F-T; $v_{f m}$ denotes P-wave velocity of specimen after F-T; and $v_{s}$ denotes $\mathrm{P}$-wave velocity $(\mathrm{m} / \mathrm{s})$ of the sample dried before the test.

The relationship between mass loss rate, F-T coefficient, $\mathrm{P}$-wave velocity loss rate, and F-T times is shown in Figure 5. It can be seen that the F-T coefficient of tuff specimens decreases with the increase in F-T cycles, and the rate of reduction of F-T coefficient of the first 10 times is obviously less than that of 20 times and 30 times; the mass loss rate increases with the increase in F-T cycles, and the increase rate of mass loss rate of the first 10 times is obviously greater than that of 20 times and 30 times; the loss rate of longitudinal wave velocity increases with the F-T cycles. The increase rate of $\mathrm{P}$-wave velocity loss rate of the first 10 times is greater than that of 20 times and 30 times. It is well known that water ice phase change will produce frost heaving force. The frost heave of ice promotes the formation of microcracks around minerals, and the microcracks increase with the increase in F-T cycles. The reason why the F-T coefficient decreases with the increase in F-T times can be attributed to the frost heaving effect of ice. When the F-T cycles are less, the F-T damage occurs on the surface of the specimen, which has little effect on the strength of the specimen. Therefore, the F-T coefficient decreases very little. With the increase in F-T times, the internal damage of tuff specimen is intensified, which makes the compressive strength of rock sample decrease. Therefore, the frost resistance coefficient also decreases. With the change of F-T cycles, the increase in mass loss rate in the first 10 cycles is significantly greater than that in 20 cycles and 30 cycles. The reason is that the rock specimen is in a slightly weathered state, and the F-T damage is mainly concentrated on the surface of the rock specimen when the F-T times are less. The decrease in the rock mass is mainly caused by the damage and spalling of the surface materials. With the increase in the F-T times, the 


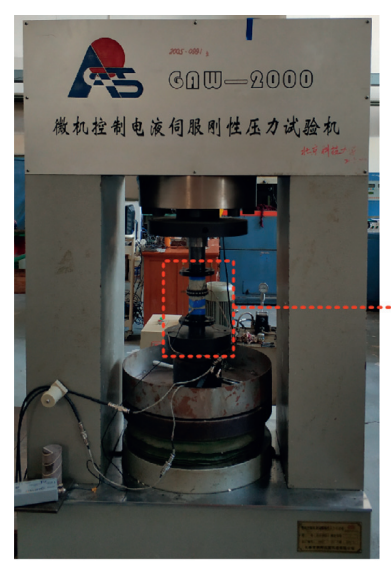

(a)

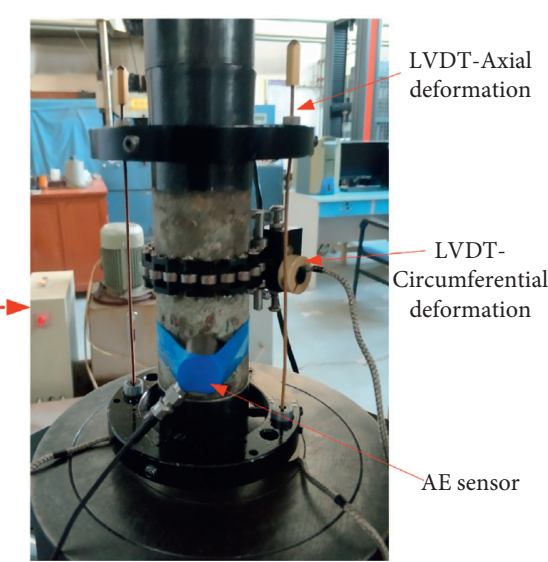

(b)

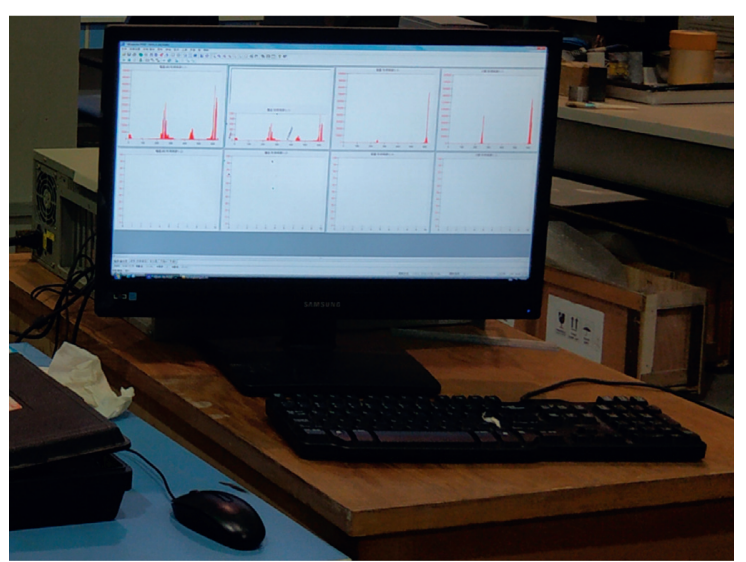

(c)

Figure 4: Test equipment: (a) GAW-2000 rock mechanical testing machine; (b) LVDT system and AE (AE) sensors; (c) AE21C AE monitoring system.

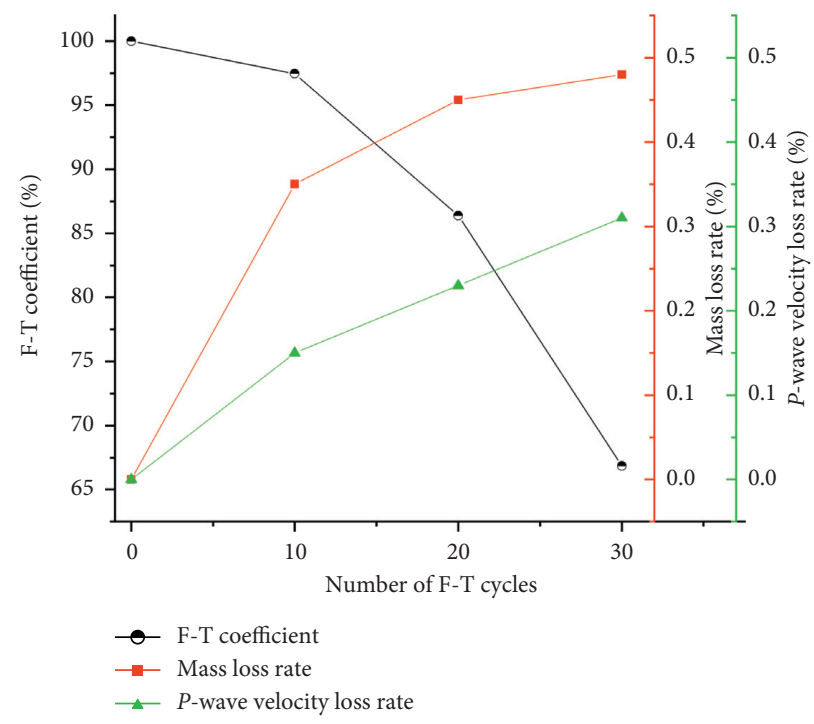

Figure 5: Relationship curves of the F-T coefficient, mass loss rate, and the P-wave velocity loss rate with the F-T cycles.

main body of the F-T damage transfers to the inner part of the specimen, and the surface material spalling decreases, while the internal damaged material does not separate from the specimen, thus making the specimen growth trend of mass loss rate slowed down. The change trend of $\mathrm{P}$-wave velocity loss rate and mass loss rate is approximately the same. The change trend of F-T coefficient, mass loss rate, and longitudinal wave velocity loss rate can be mutually verified, which reflects that when the F-T cycles are less, the F-T damage of rock is mainly concentrated on the surface of rock. The influence of F-T cycles on F-T coefficient, mass loss rate, and $\mathrm{P}$-wave velocity loss rate reflects the development process of rock F-T damage from the surface to the inside.

By observing and recording the $\mathrm{F}-\mathrm{T}$ damage process of tuff specimens, it was found that each specimen had different degrees of F-T damage phenomena such as peeling, cracking, and block dropping. In this study, the F-T damage of specimens was observed by using an electron microscope, as shown in Figure 6. There are two peeling off points on the surface of FT1-1 specimen; there are two peeling off points on the surface of FT1-2 specimen, a crack about $0.346 \mathrm{~mm}$ in width, and one peeling off on the circular surface; two peeling off points are found on the curved surface of FT1-3 specimen, and one crack is about $0.424 \mathrm{~mm}$ wide, and one peeling is found on the circular surface; the surface of FT2 specimen has one peeling off and one crack with a width of $0.486 \mathrm{~mm}$, and there is one peeling and one large falling block on the surface of FT3 specimen. There are two peeling off points and a crack about $0.394 \mathrm{~mm}$ in width and two peeling spots on the circular surface; there are two peeling off points on the curved surface of FT4 specimen, and two cracks with the width of $0.238 \mathrm{~mm}$ and $0.532 \mathrm{~mm}$, respectively, and there is one peeling off and one large falling block on the circular surface. The more F-T cycles the tuff specimens experience, the more serious the F-T damage is. These damages are mainly due to water migration effect and frost 


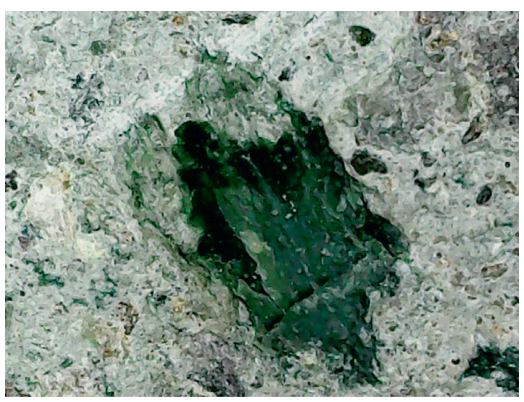

(a)

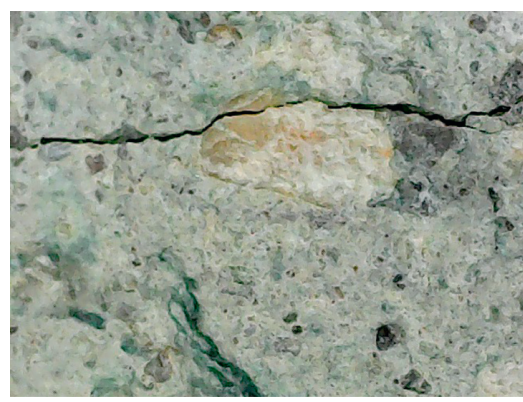

(b)

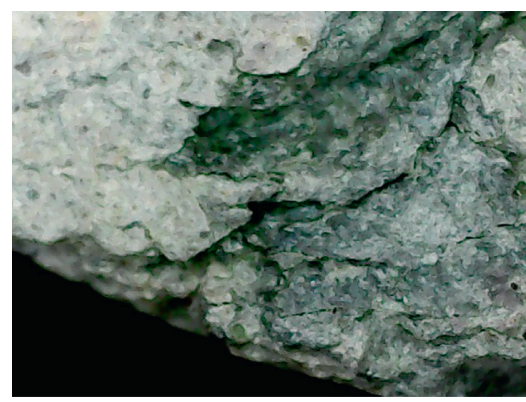

(c)

FiguRE 6: Different degrees of damage were showed in the rock sample surface after 30 F-T cycles: (a) peeling; (b) cracking; (c) large flakes.

heaving caused by water ice phase transition. Frost heaving pressure drives the initiation and expansion of these damages. Due to the different F-T damage of each specimen, different mechanical properties were formed.

3.2. Stress-Strain Curve. Figures $7(\mathrm{a}) \sim 7(\mathrm{~h})$ show the axial, transverse, and volumetric stress-strain curves of rock samples NF1, FT1-3, NF2, FT2, NF3, FT3, NF4, and FT4. Figures 7(a) and 7(b) show NF1 and FT1-3 specimens, respectively. Under condition 1 , the peak stress is $55.74 \mathrm{MPa}$ and $37.26 \mathrm{MPa}$, and the peak strain is $0.32 \%$ and $0.29 \%$, respectively. The uniaxial compressive strength of FT1-3 specimen is about $33 \%$ lower than that of NF1 specimen. The volume stress-strain curve is a comprehensive reflection of specimen deformation. The deformation of the two rock samples is first under compression and then expansion. The volume of FT1-3 specimen begins to expand when the axial stress is small (about $22.5 \mathrm{MPa}$ ), while the volume of NF1 specimen begins to expand after reaching the peak stress (about 55.7 MPa). After 30 F-T cycles, cracks and other F-T damages occurred in the samples, which made the volume of the samples begin to expand earlier. Figures $7(\mathrm{c})$ and $7(\mathrm{~d})$ show NF2 and FT2 specimens, respectively. The loading conditions of the specimens are condition 2. The peak stress is $88.65 \mathrm{MPa}$ and $42.48 \mathrm{MPa}$, and the peak strain is $0.54 \%$ and $0.34 \%$, respectively. The peak stress of FT2 specimen decreases by $52 \%$ compared with NF2 specimen. From the loading path shown in Figure 3(b), the stress-strain curve consists of two parts: one is the stress increase section and the other is the fatigue cycles loading and unloading section. Under the influence of F-T damage, their morphology is completely different, and they go through 5 and 2 fatigue cycles before failure. After $30 \mathrm{~F}-\mathrm{T}$ cycles, there are internal fractures and plastic deformation fractures. At low stress levels, a hysteresis curve is formed. It can be seen from the volume stress-strain curve that the volume of the two samples experienced the process of compression first and then expansion. The damage of rock is much more serious in each stress increasing stage than in the fatigue cycles stage. In the loading and unloading stage of fatigue cycles, the initial fatigue mode is sparse, and with the loading and unloading, the fatigue mode becomes more intensive. The damage in the fatigue loading stage is smaller than that in the stress increasing stage. Figures $7(\mathrm{e})$ and $7(\mathrm{f})$ show NF3 and FT3 specimens, respectively, and the loading condition of the specimens is condition 3. The peak stress is $50.22 \mathrm{MPa}$ and $45.51 \mathrm{MPa}$, and the peak strain is $0.30 \%$ and $0.32 \%$, respectively. The peak stress of FT3 specimen is about 9\% lower than that of NF3 specimen. Before the failure, it experienced two fatigue cycles. It can be seen from the volume stress-strain curve that the volume of the two samples experienced the process of compression first and then expansion. The damage of rock is much more serious in each stress increasing stage than in the fatigue cycles stage. The shape of stress-strain curves of NF3 and FT3 specimens is similar. Comparing the stress-strain curves of NF3 and NF2, it can be seen that the peak stress and peak strain of NF3 specimen are much lower. When the axial stress is about $46 \mathrm{MPa}$, the radial strain of NF3 specimen increases suddenly. Figures $7(\mathrm{~g})$ and $7(\mathrm{~h})$ show NF4 and FT4 specimens, respectively. Under condition 4, the peak stress is $61.13 \mathrm{MPa}$ and $51.23 \mathrm{MPa}$, and the peak strain is $0.34 \%$ and $0.31 \%$, respectively. The peak stress of FT4 specimen is about $16 \%$ lower than that of nf 4 specimen. From the stress-strain curves shown in Figures $7(\mathrm{~g})$ and $7(\mathrm{~h})$, the reloading curve crosses the unloading curve below the unloading point and forms a hysteresis loop. There are 5 and 4 hysteresis loops in NF4 and FT4 specimens, respectively. The failure of tuff specimens occurred in the stage of stress increase. The postpeak stress-strain curves show different shapes, indicating different failure modes. For NF2 and FT2 samples and NF4 and FT4 samples, with the passage of test time, they gradually fail; for NF1 and FT1-3 samples and NF3 and FT3 samples, sudden failure occurs, and the stress-strain curves show a sudden drop.

3.3. Cyclic Deformation Characteristics. Loading conditions 2 and 3 belong to cyclic loading modes with different amplitudes, and both have the fatigue loading stage and stress increasing stage. 30 cycles were carried out in each fatigue loading stage. The maximum axial strain, lateral strain, and volumetric strain are analyzed as shown in Figure 8 . The number after the rock sample number in the figure is the cyclic loading stage of the rock sample, such as NF2-1, which is the first cyclic loading stage of NF2 rock sample. It can be seen that the strain increases with the increase in the loading stage. In Figure 8(a), for the maximum axial strain, the deformation increment increases with the increase in the fatigue stage, indicating that the damage in the rock is 

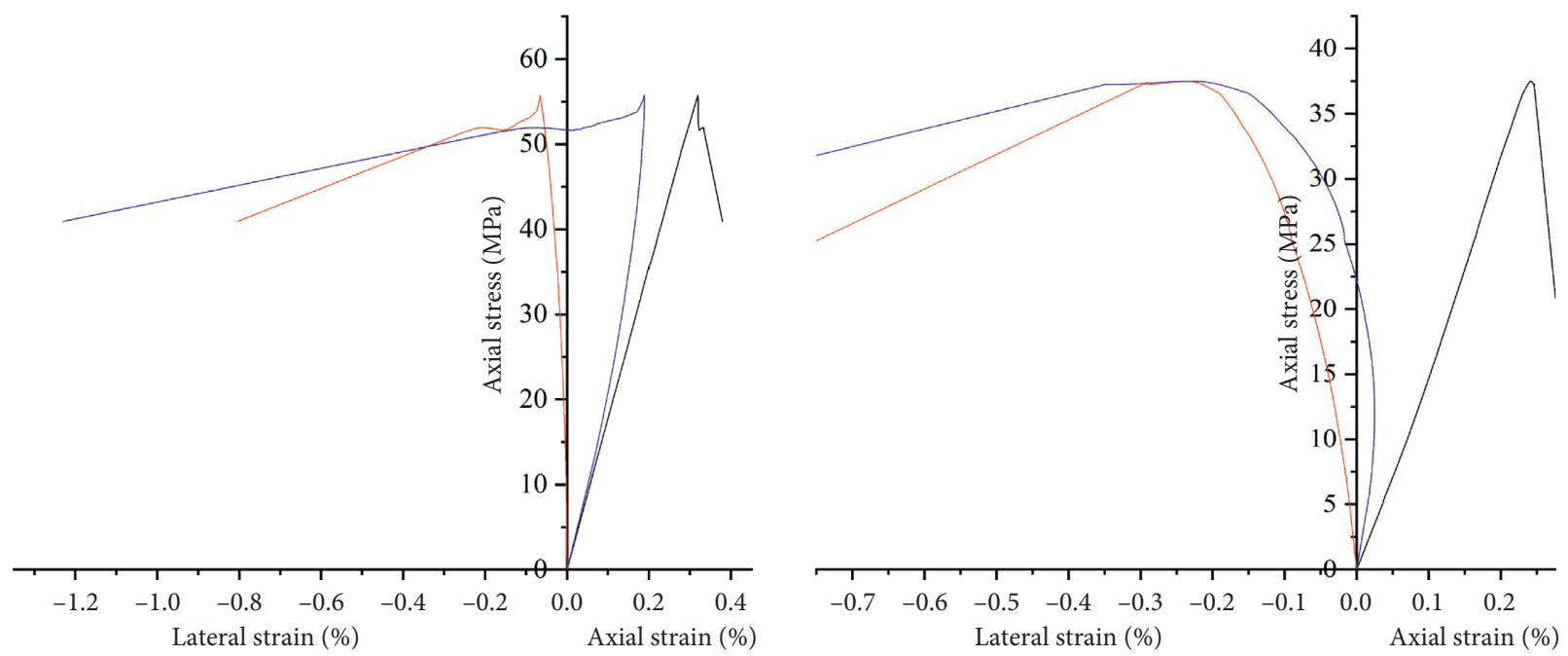

_ Axial strain

_ Axial strain

Lateral strain

_ Volumetric strain

Lateral strain

_ Volumetric strain

(a)

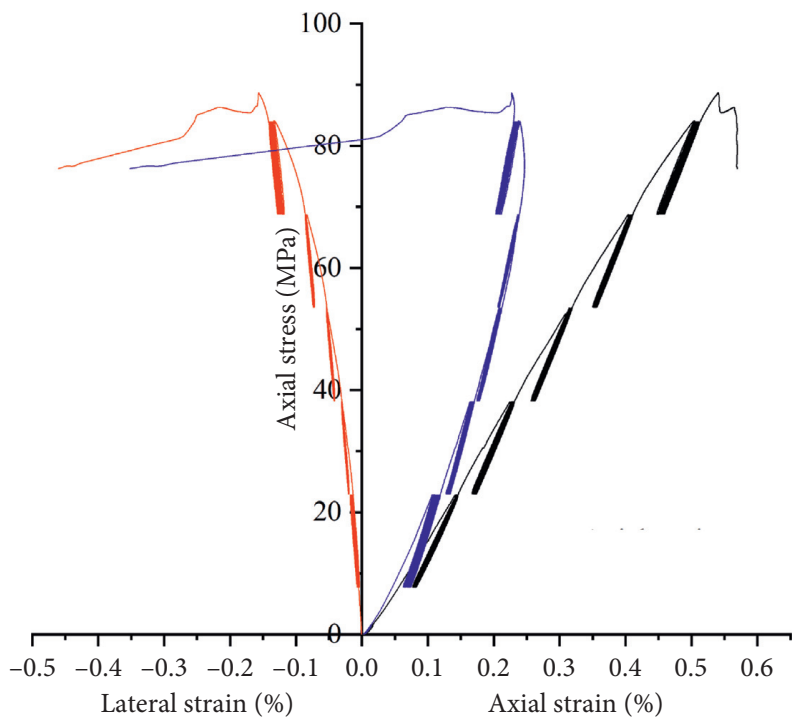

(b)

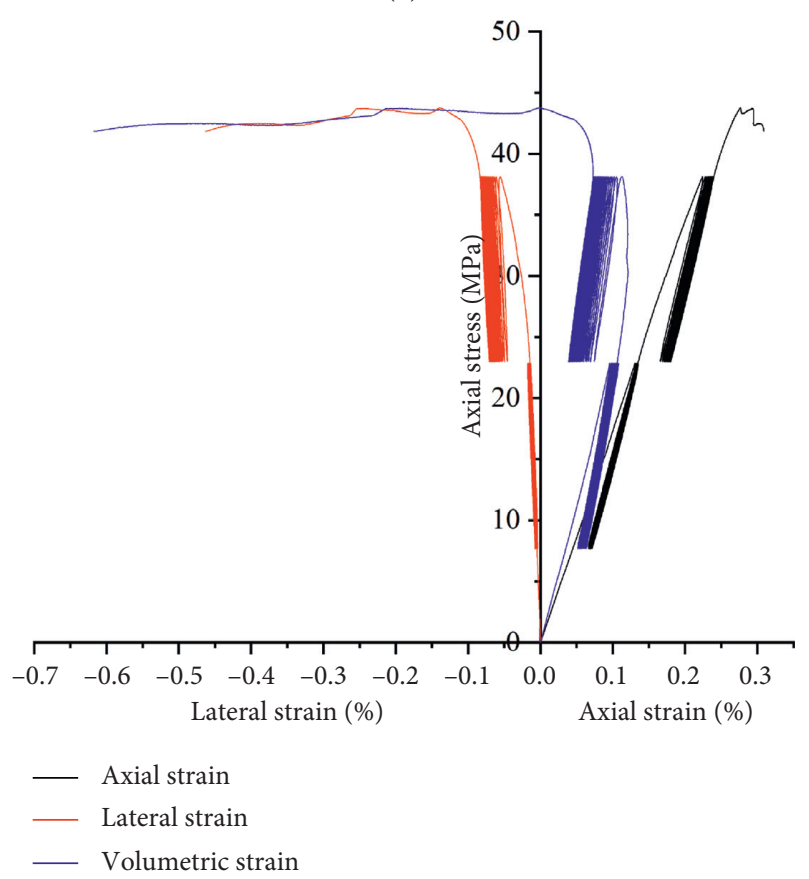

(c)

(d)

Figure 7: Continued. 


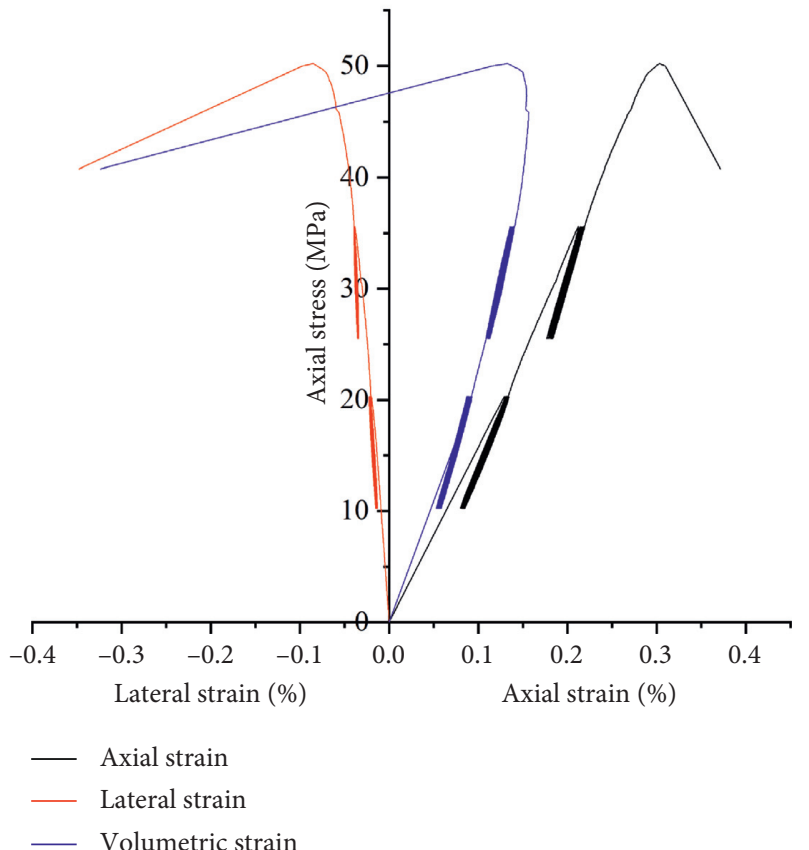

(e)

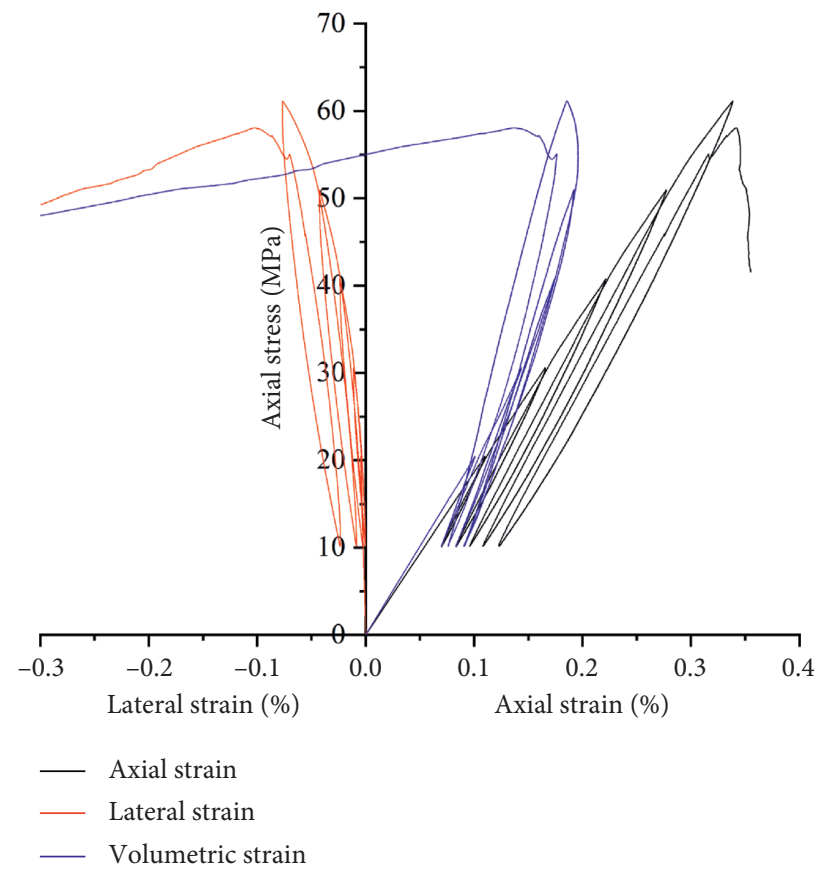

(g)

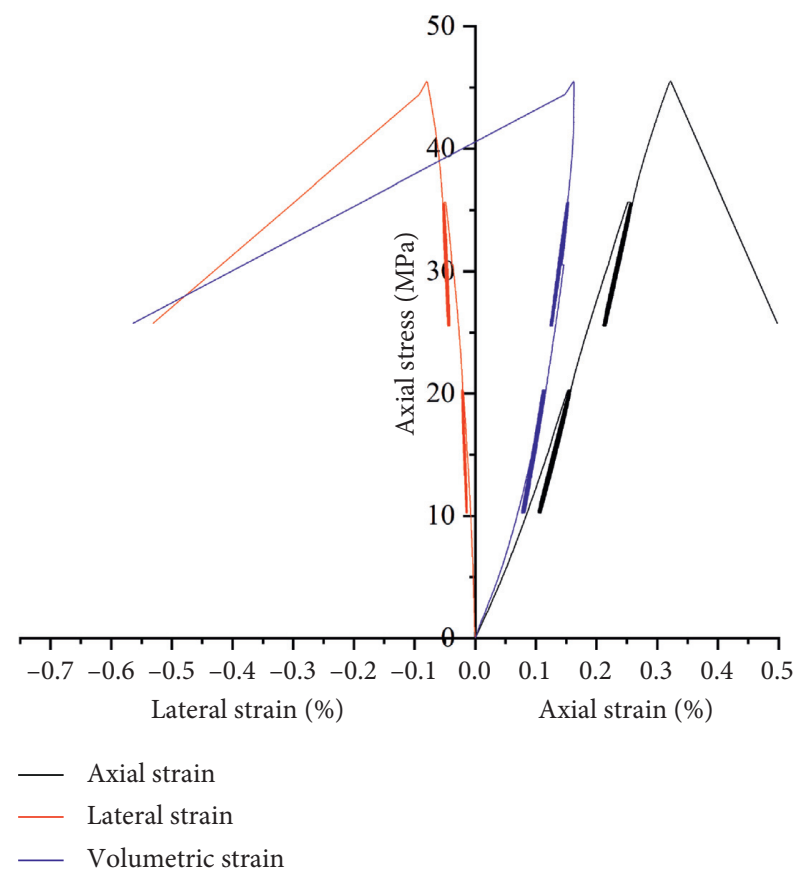

(f)

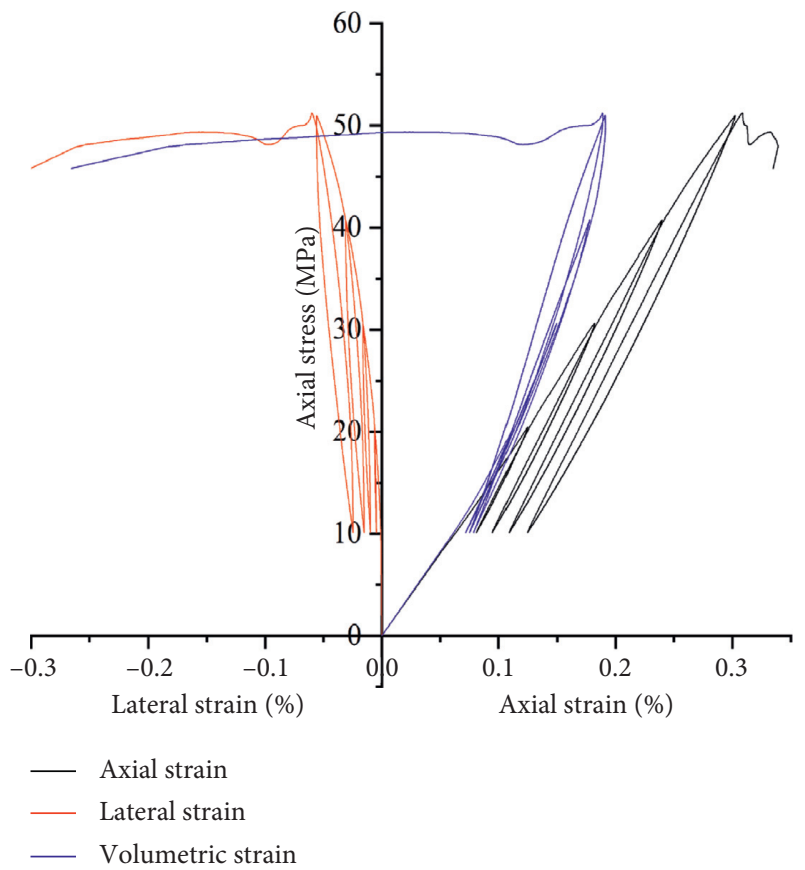

(h)

FiguRE 7: The stress-strain curves of rock samples subjected to different stress paths: (a) NF1; (b) FT1-3; (c) NF2; (d) FT2; (e) NF3; (f) FT3; (g) NF4; (h) FT4.

increasing. In addition, the overall maximum axial strain of NF2 is the largest and FT2 is the smallest. For the maximum lateral strain (Figure 8(b)), since it is measured by the LVDT system installed in the center of the rock sample, it only reflects the local deformation of the rock sample. The ultimate radial strain of NF2 rock sample is the maximum value, and NF3 is the minimum value. The volume strain is a comprehensive reflection of the axial and lateral deformation of the specimen, as shown in Figure 8(c). When the load is applied to the specimen, the volume strain of all specimens is positive, which means that the volume of all specimens is always in the compression state during the cyclic loading stage. The volume strain of FT2 decreases from $11.27 \%$ to $7.35 \%$ in the second cyclic loading stage, indicating that the volume of NF2 specimen has begun to expand in the cyclic loading stage. In addition, the volume 


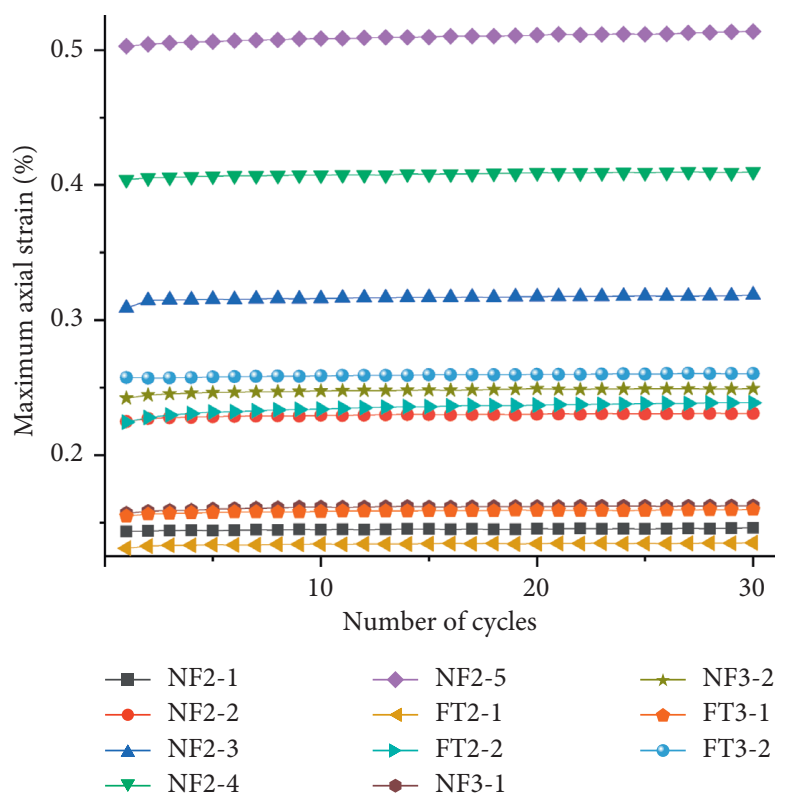

(a)

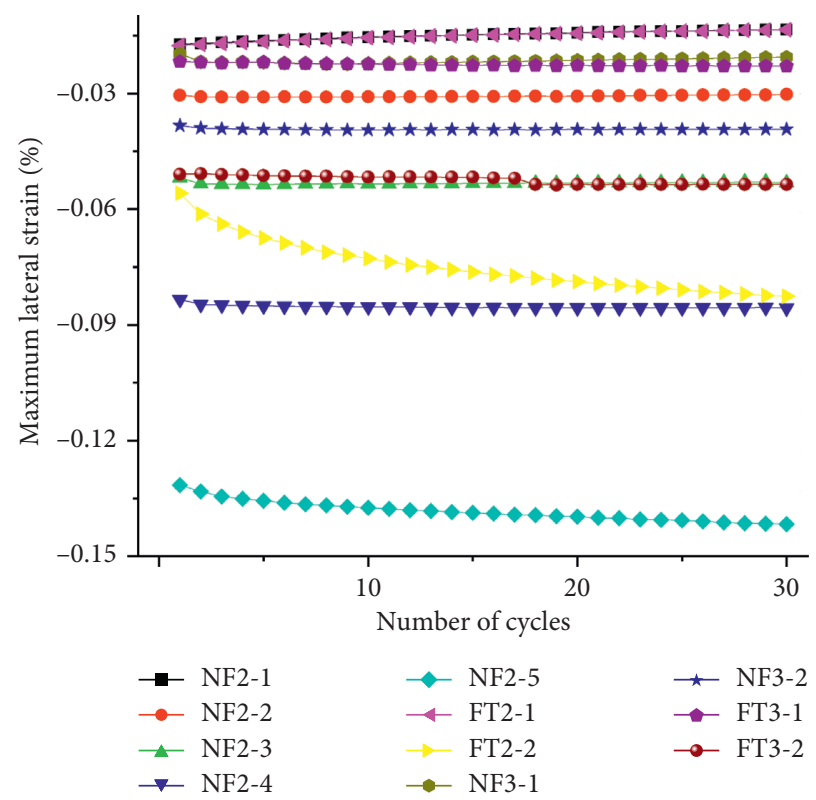

(b)

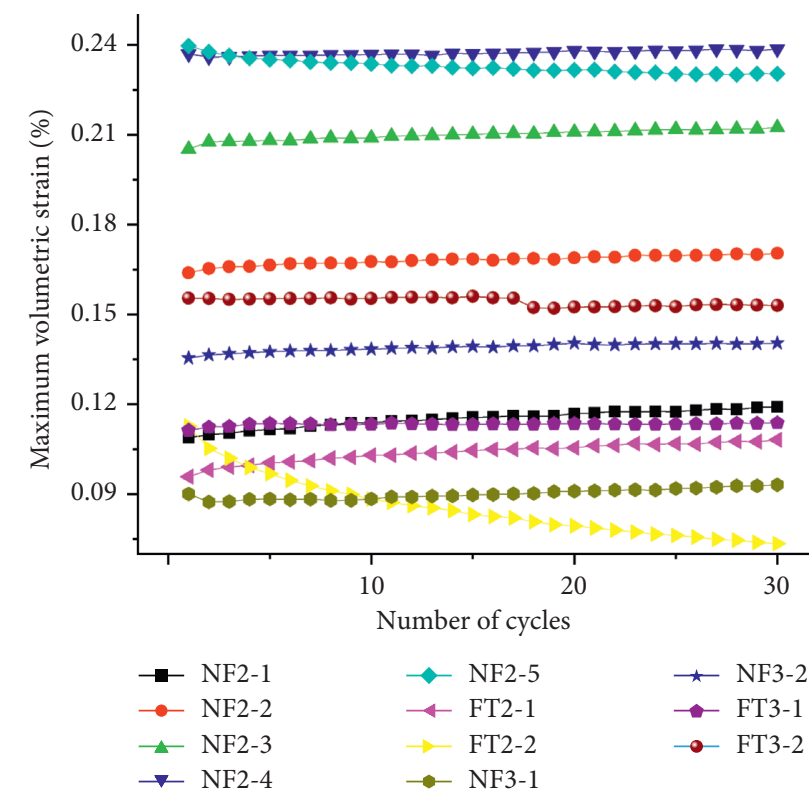

(c)

FIGURE 8: The relationship between the maximum strain and the number of cycles in each cyclic loading stage: (a) maximum axial strain; (b) maximum lateral strain; (c) maximum volumetric strain.

strain of other specimens has little change in the cyclic loading stage. Finally, the volume strain of NF2 is the largest and FT2 is the smallest.

NF4 and FT4 of tuff samples undergo equal incremental cyclic loading and unloading, and irreversible plastic deformation occurs when unloading to the minimum stress. With the increase in the number of cycles, the plastic strain value gradually increases, as shown in Figure 9. It can be seen from the figure that the plastic strain of FT4 is greater than that of NF4 when the cyclic loading and unloading period is the same. The plastic strain of NF4 and FT4 is $0.54 \times 10^{-3}$ and $0.61 \times 10^{-3}$, respectively. The main reason is that after F-T cycles, cracks and other F-T damages occur in the specimen, resulting in the plastic strain and deformation rate increasing with the increase in loading and unloading cycles. When the stress increment is the same, the plastic strain and plastic strain rate of FT4 specimen are greater than those of NF4.

3.4. AE Count/Energy Analysis. The stress-strain curve reflects the macroscopic fracture evolution characteristics of tuff samples. The AE activity recorded in the deformation process of the sample provides a basis for us to understand 


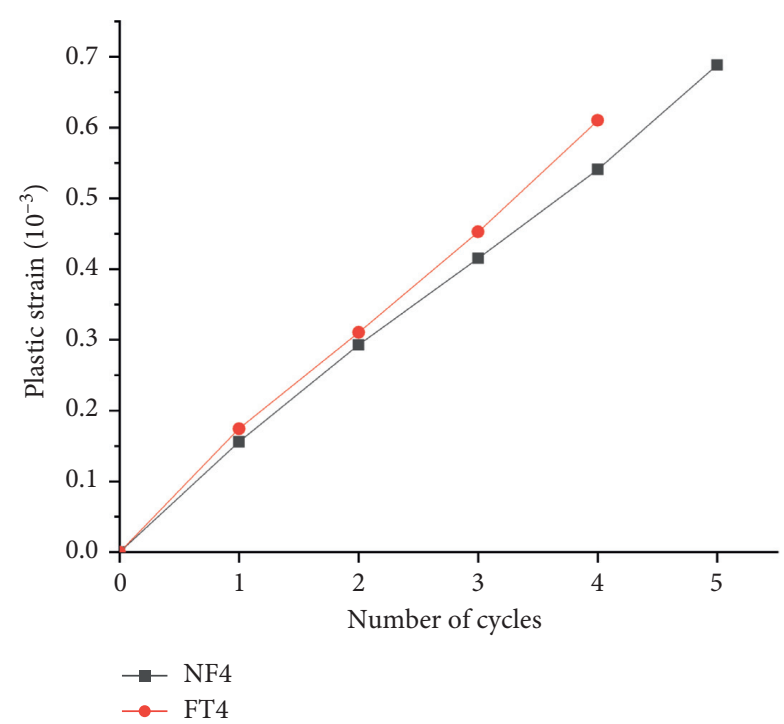

Figure 9: Curves of plastic strain with number of cycles.

the microfracture process of rock. The AE count statistics of our experiment are shown in Figure 10. Figures 10(a) and 10(b) are, respectively, NF1 and FT1-3 specimens, both of which have the maximum counting rate when the whole rock is destroyed. The comparison of the two figures shows that the AE events of NF1 rock sample are more from the beginning of loading to about $120 \mathrm{~s}$, and then to the failure of rock sample, the AE events are relatively less. When the rock sample is close to failure, $\mathrm{AE}$ events increase sharply. The $\mathrm{AE}$ events of FT1-3 rock samples are relatively uniform from the beginning of loading to the time of failure. When the rock sample is close to failure, $\mathrm{AE}$ events increase sharply. It can be seen from the AE cumulative count curve that the NF1 AE cumulative count curve is relatively stable before rock sample failure, while the FT1-3 AE cumulative count curve continues to increase. The cumulative AE count of FT1-3 (45077) is less than that of NF1 (55457). This is due to the influence of F-T damage such as cracks, which results in different AE phenomena between FT1-3 and NF1.

Figures $10(\mathrm{c})-10(\mathrm{f})$ show the counting curves of NF2, FT2, NF3, and FT3 specimens, respectively. It can be seen from the $\mathrm{AE}$ count curve that $\mathrm{AE}$ events jump at the beginning of each fatigue loading stage. Relatively few $\mathrm{AE}$ events were recorded in each fatigue loading stage. This means that the cumulative damage in the fatigue loading stage occurs at the stress increasing stage. In the stress increasing stage, a large number of AE counts are recorded, and the initiation and propagation of cracks play a leading role in rock failure. As can be seen from the AE cumulative count curve, the cumulative AE count of FT2 (116024) is less than that of NF2 (147144), and that of FT3 (31811) is less than that of NF3 (8787879). The cumulative AE count curve is ladder shaped, which indicates the sudden increase in $\mathrm{AE}$ events in each stress increasing stage.

Figures $10(\mathrm{~g})$ and $10(\mathrm{~h})$ show NF4 and FT4 specimens, respectively. The loading conditions of the specimens are equal incremental cyclic loading and unloading. By comparing the loading and unloading processes in Figure 10(g), it is found that the AE phenomenon appears only when the stress exceeds the stress of the last loading. However, there is no $\mathrm{AE}$ phenomenon in the unloading process, or the $\mathrm{AE}$ phenomenon can be ignored. The cumulative $\mathrm{AE}$ count of NF4 specimen increases slowly in a ladder shape before the specimen is damaged and increases sharply when the specimen is damaged. The cumulative AE count of FT4 specimen increased step by step. Before failure, the $\mathrm{cu}-$ mulative AE count is large; after failure, the cumulative $\mathrm{AE}$ count increases, but there is no sharp increase like NF4 specimen. The cumulative AE count of FT4 (164341) was less than that of NF4 (250724). From the comparison of loading and unloading process in Figure 10(h), it can be seen that there are more $\mathrm{AE}$ events in the first two loads, and very few $\mathrm{AE}$ events occur in the third and fourth loading. However, in the middle and later stage of the fourth unloading, the $\mathrm{AE}$ phenomenon was more concentrated and obvious. This indicates that when the stress level reaches a certain value, the brittle failure of tuff will also occur during unloading. Combined with the stressstrain curve, it can be seen that after the local failure of the rock with cracks and other F-T damage, the rock can adjust its internal structure to enhance its bearing capacity until the overall failure.

In general, the different failure modes can be seen from the AE counting curve. The macroscopic stress-strain curves reveal different failure characteristics in the postpeak stage. The AE counting response is consistent with the change of the stress-strain curve. According to the $\mathrm{AE}$ cumulative curve, under the same stress path, the cumulative AE count of frozen and thawed rock samples is less than that of non F-T rock samples. A large number of AE activities occurred in the postpeak stage, indicating the existence of block sliding between the fractured rock samples. After F-T cycles, there are cracks and other F-T damages in tuff samples. These damages affect the initiation and expansion of cracks and also affect the initiation and expansion of new cracks under different stress paths. 


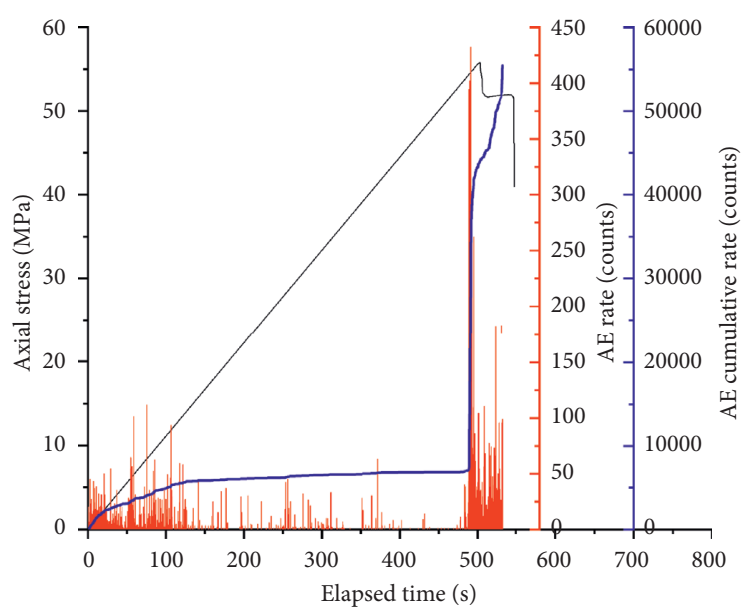

— Axial stress

AE rate

Accumulative rate

(a)

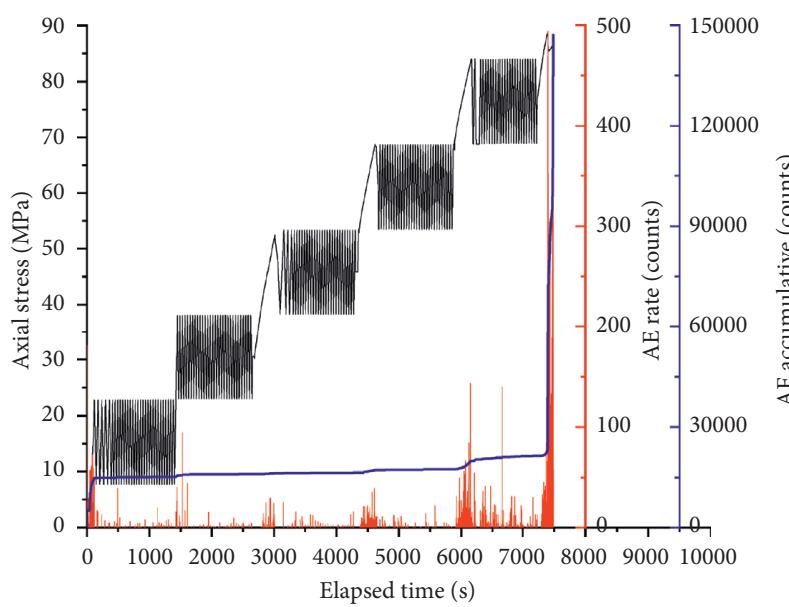

_ Axial stress

AE rate

- Accumulative rate

(c)

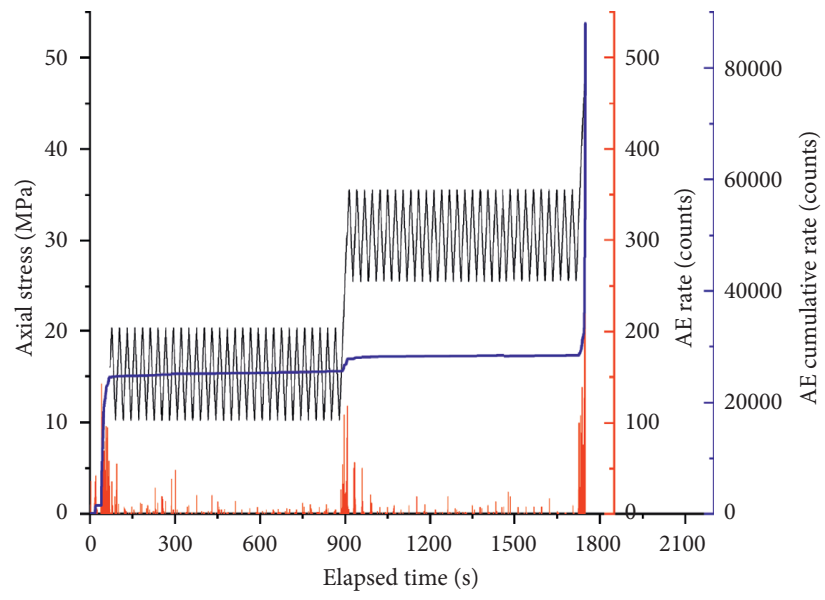

— Axial stress

AE rate

- Accumulative rate

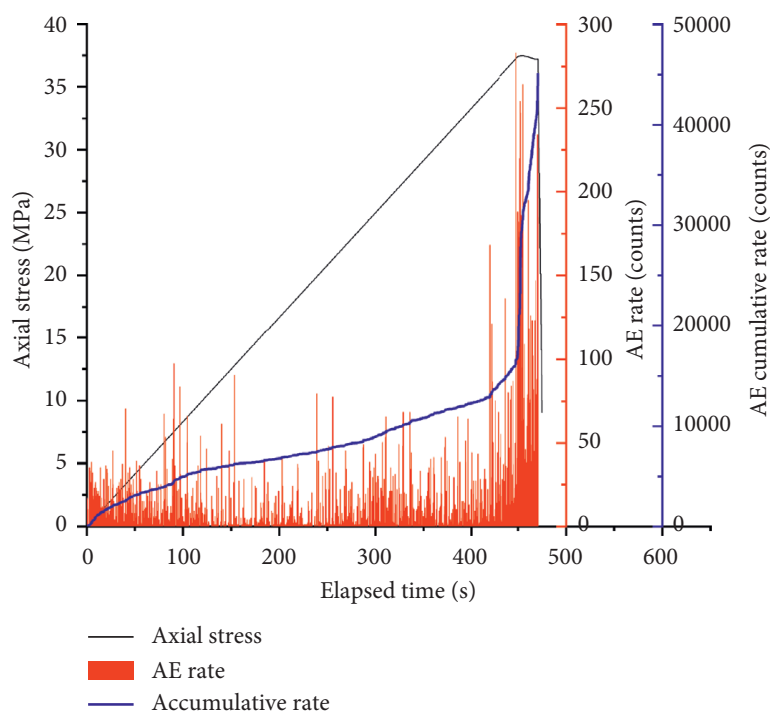

(b)

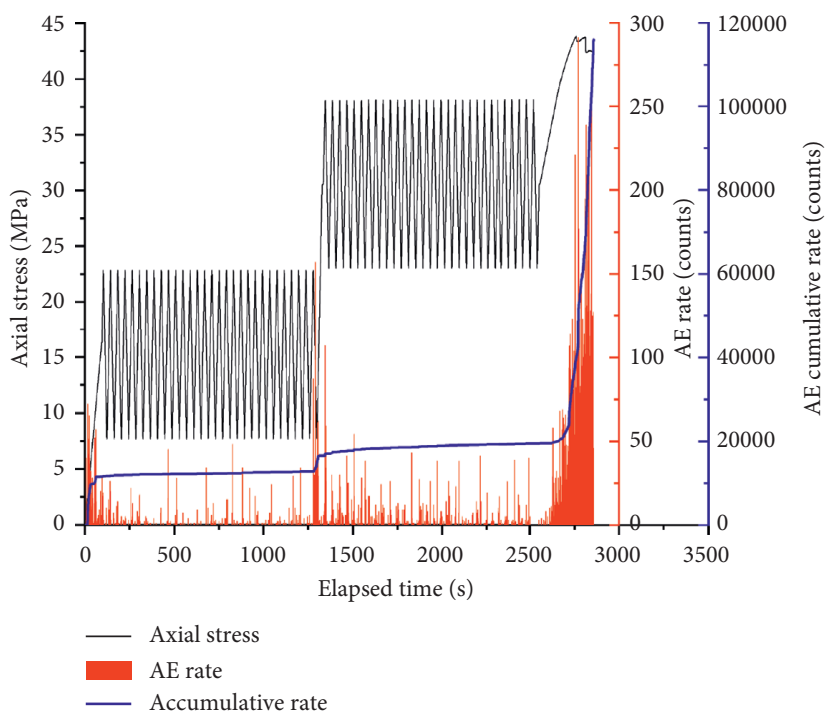

(d)

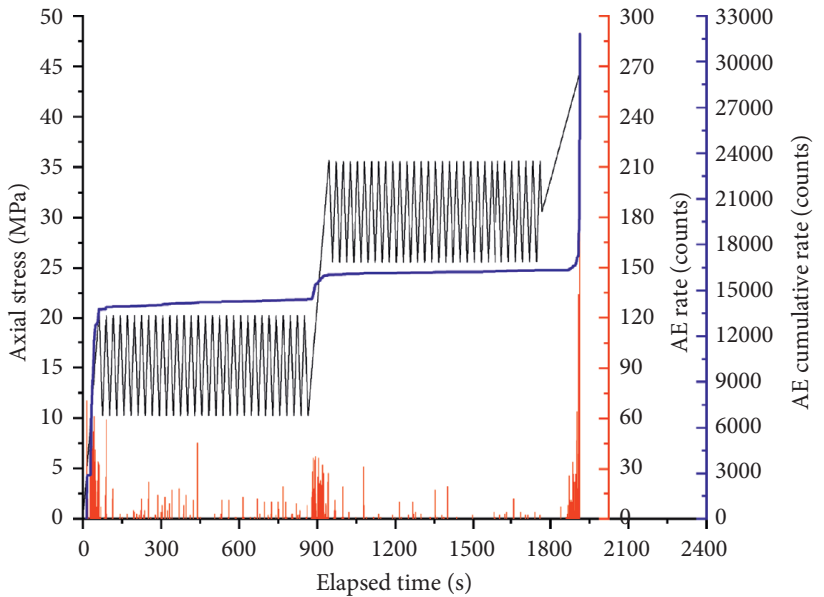

_ Axial stress

AE rate

- Accumulative rate

(e)

Figure 10: Continued. 


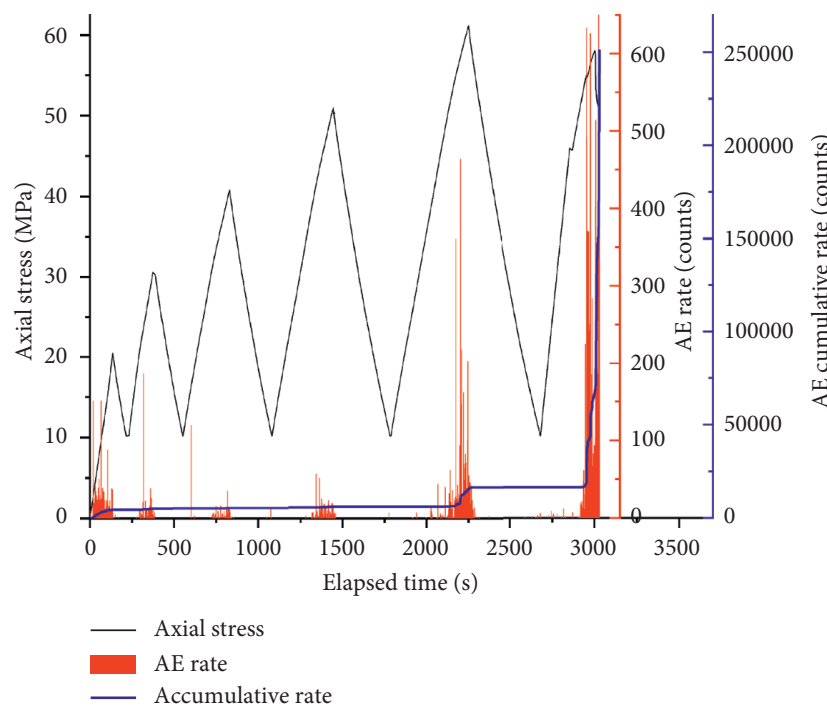

(g)

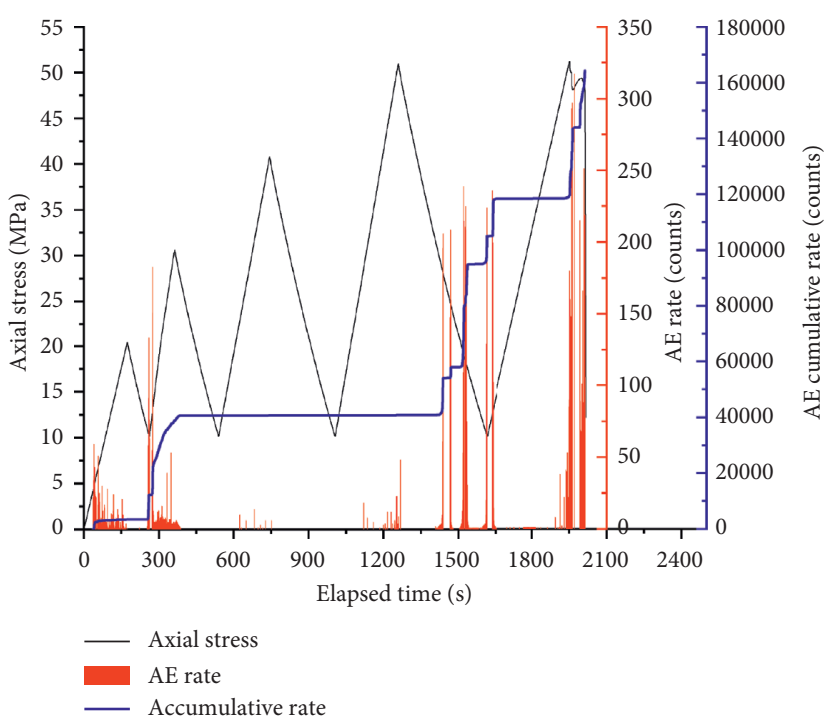

(h)

Figure 10: The counting rate of rock samples subjected to different stress paths: (a) NF1; (b) FT1-3; (c) NF2; (d) FT2; (e) NF3; (f) FT3; (g) NF4; (h) FT4.

In addition to $\mathrm{AE}$ counting, $\mathrm{AE}$ energy is also an effective parameter to characterize rock fracture characteristics. The $\mathrm{AE}$ energy monitored by using the $\mathrm{AE}$ sensor is an absolute energy, which is generally defined as the measured area under the corrected signal envelope. It is a product of event time span and amplitude, and its unit is mv. $\mu$ s. Because AE energy is sensitive to amplitude and duration and less dependent on operating frequency and voltage threshold, this parameter is usually used to explain the magnitude of source events in AE counting, which can better reflect the initiation and propagation of cracks [38-40].

The change of AE energy with axial stress and test time is shown in Figure 11. It can be seen from the figure that the change law of $\mathrm{AE}$ counting rate and energy is basically the same, and the conclusion that the change of AE energy is similar to that of the count rate can be obtained. Because AE energy is sensitive to amplitude and duration and it is less dependent on operating frequency and voltage threshold, $\mathrm{AE}$ energy parameter is usually preferred to explain the magnitude of source events, which can better reflect the initiation, propagation, and coalescence of cracks. The results show that the AE energy curve jumps in the stress increasing stage. However, the stress corresponding to the jumping time does not always increase. The jump time is not only related to the initiation of new cracks but also to the existing fractures. It can be seen from Figure 11(b) that for the FT1-3 specimen, when the load is around $230 \mathrm{~s}$, local failure occurs at the weak structural plane, and the release of elastic strain energy increases suddenly. Compared with the energy release in the failure stage after the peak stress, the energy released during local failure is more than that after the peak strength. The failure after the peak is mainly the block slip, and the released strain energy is relatively small. This is mainly due to the interaction between the existing
F-T damage cracks and the newly excited cracks after local failure, which changes the rock structure and affects the energy accumulation. However, for other specimens except FT1-3, it can be seen that the elastic strain energy stored at the moment of failure is suddenly released. At this time, the energy release rate is the largest, and the cumulative $\mathrm{AE}$ energy increases suddenly. It can be seen from Figure 11(h) that for FT4 sample, when the accumulated elastic energy of tuff exceeds the dissipation energy of local failure, the brittle failure of tuff will be easily perceived during unloading. This is consistent with the conclusion of $\mathrm{AE}$ count rate.

On the whole, AE parameters show a process from small to large and also show the stage of fracture progress. The energy release rate and count rate are the largest when the rock sample is destroyed as a whole. However, the rock samples with cracks and other damages caused by F-T are not consistent with the conventional change law, which is mainly related to the interaction between $\mathrm{F}-\mathrm{T}$ damage and newly excited fractures.

3.5. Analysis of AE Peak Frequency Characteristics. It is well known that the study of AE response in rock fracture process shows that the stress wave in the form of AE signal can be used to understand the energy dissipation process of crack initiation and propagation. $\mathrm{AE}$ is a signal composed of multiple frequencies. The waveform frequency and amplitude of different $\mathrm{AE}$ sources are different. Waveform characterization can reflect the type, number, and size of fractures so as to better characterize the process of rock fracture. The existing research results show that the main frequency characteristics of $\mathrm{AE}$ can better reflect the microcracks of rock, and it is more sensitive to the $\mathrm{AE}$ number [41, 42]. In this section, we focus on the peak 


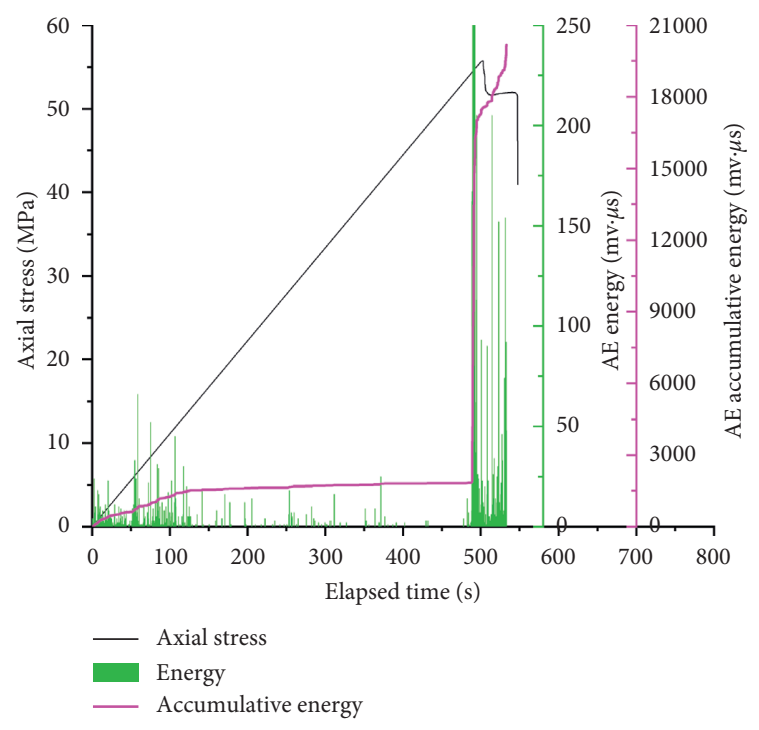

(a)

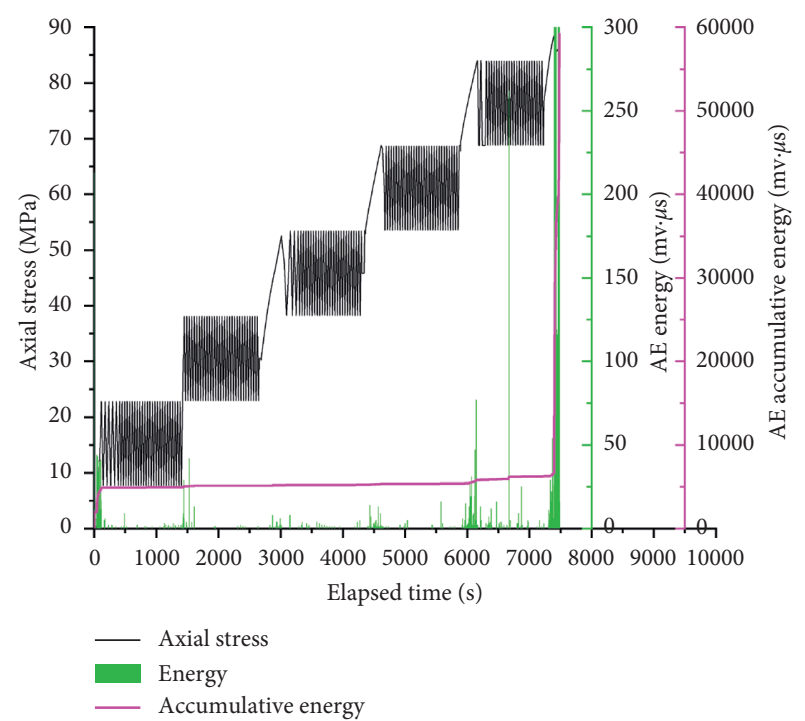

(c)

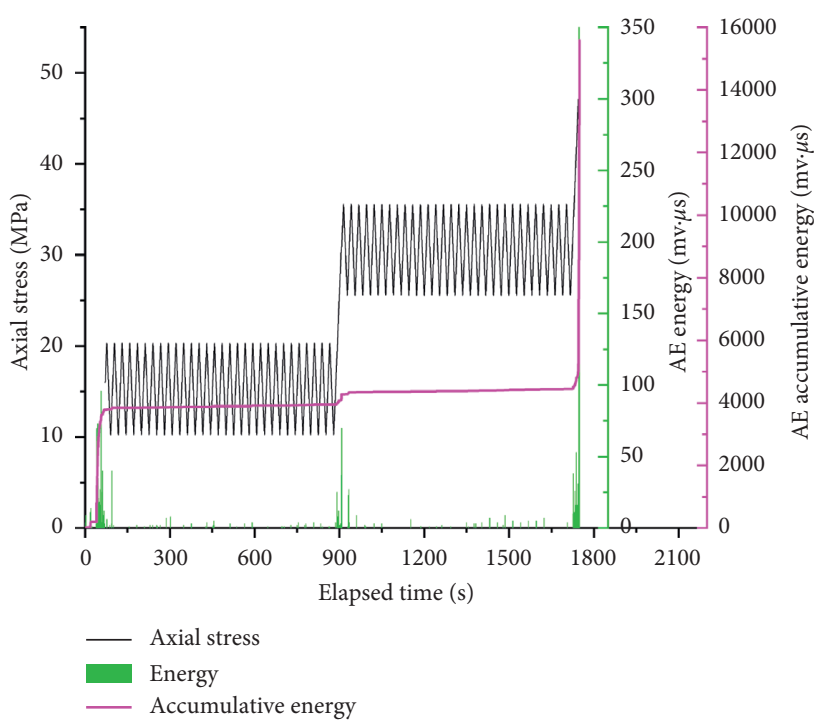

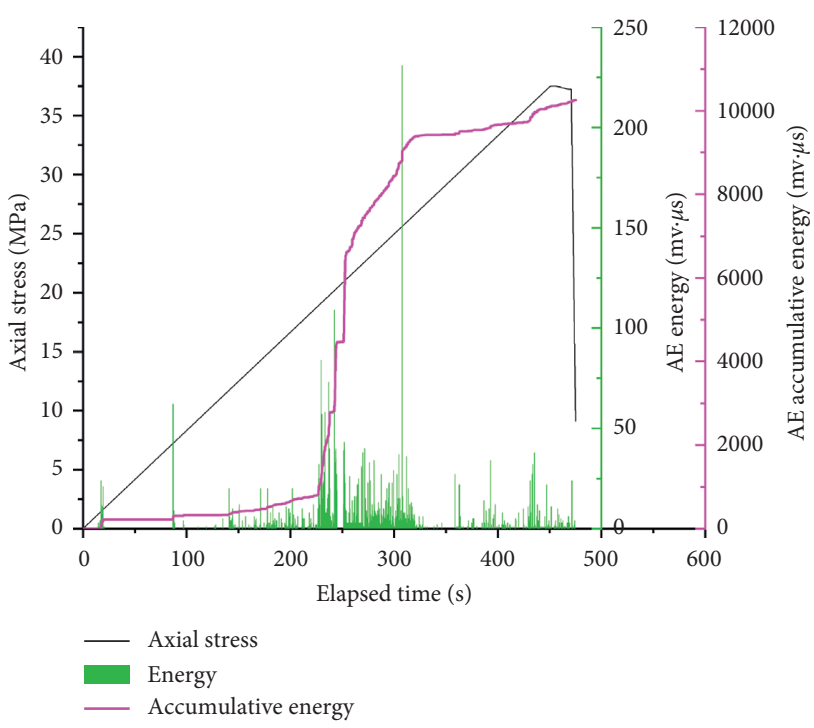

(b)

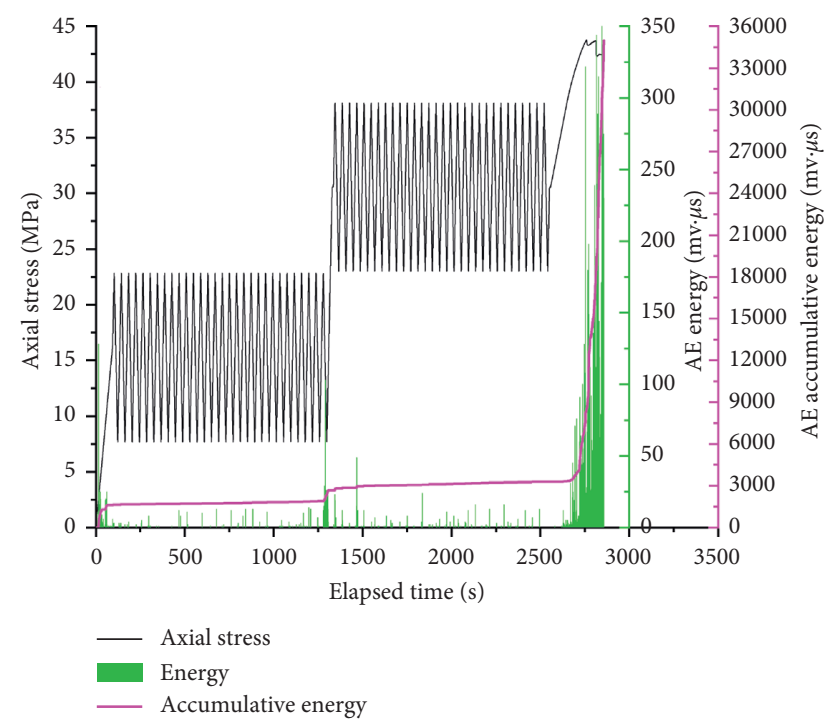

(d)

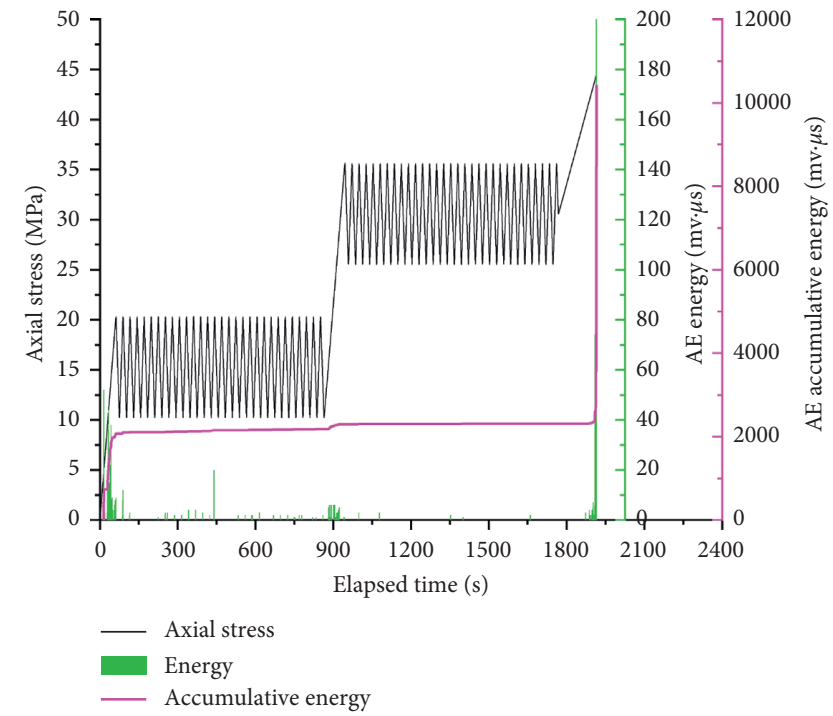

(f)

FIgURe 11: Continued. 


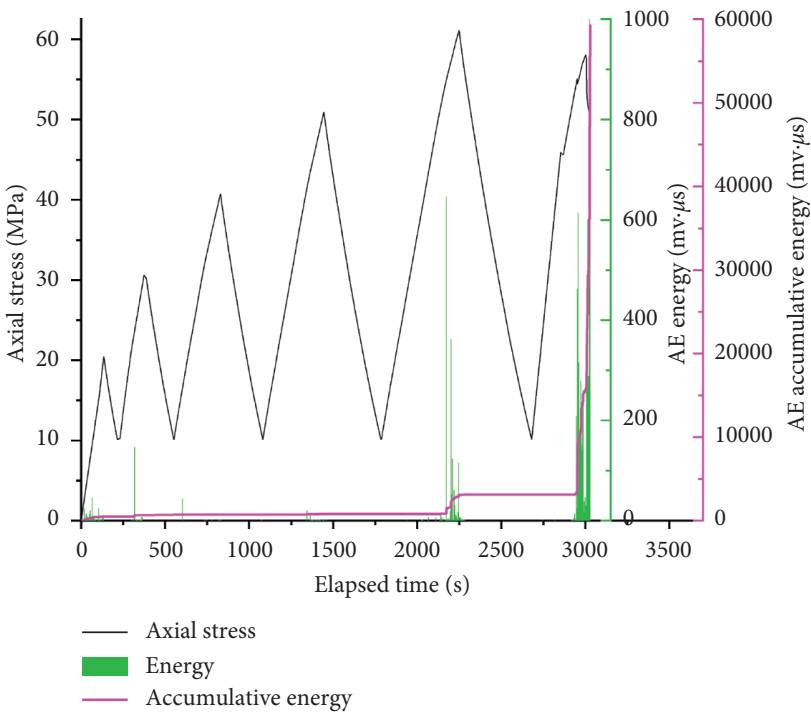

(g)

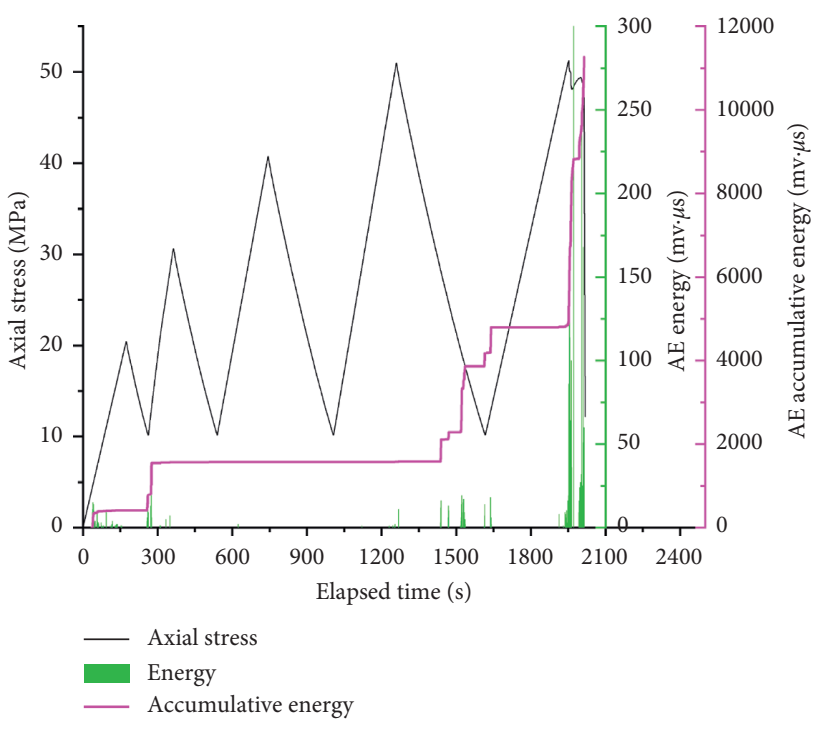

(h)

FIGURE 11: The AE energy statistics of rock samples subjected to different stress paths: (a) NF1; (b) FT1-3; (c) NF2; (d) FT2; (e) NF3; (f) FT3; (g) NF4; (h) FT4.

frequency characteristics of $\mathrm{AE}$, which is an important means to describe the process of fracture formation. The AE frequency is inversely proportional to the crack size. Generally speaking, large-scale cracks correspond to low-frequency signals and small-scale cracks correspond to high-frequency signals. The distribution of $\mathrm{AE}$ frequency band indicates the mesofracture mechanism of rock.

In this paper, fast Fourier transform (FFT) is used to transform the time domain signal into the frequency domain, and the amplitude spectrum (amplitude frequency relationship curve) of $\mathrm{AE}$ signal is obtained. The frequency corresponding to the maximum amplitude point in the amplitude spectrum is the peak frequency of AE signal. By analyzing the AE peak frequency of rock samples which have experienced different stress paths, we have obtained the relationship curve between AE signal time and peak frequency, as shown in Figure 12. Due to the influence of its own fabric, shape, environmental temperature, loading mode, and loading history, rocks in different states show their own specific frequency and have different frequency distribution. The structural characteristics of rock specimens subjected to different F-T cycles are different to some extent, which leads to the generation of $\mathrm{AE}$ signals with different frequencies in the process of deformation and failure.

It can be seen from Figure 12 that the peak frequency distribution of AE signal during the loading process of rock specimen presents the phenomenon of dense frequency bands. According to the peak frequency density, the peak frequency of each specimen is divided into three frequency bands: low-frequency band, medium frequency band, and high-frequency band. The comparison between Figures 12(a) and 12(b) shows that before the peak stress is reached, there is no high-frequency signal in NF1 specimen. But, FT1-3 specimen sends out high-frequency signal from the beginning of loading, which indicates that more small-scale cracks are formed in FT1-3 specimen from the beginning of loading. For the rock samples under the action of other stress paths, the high-frequency band has similar characteristics. The results show that the F-T rock samples have different peak frequency characteristics than the unfrozen rock samples, which indicates that the frozen thawed rock samples are more likely to produce fracture small-scale cracks from the beginning of loading. The frequency band width of different samples is different, and the spectrum bandwidth distribution is shown in Table 2.

The frequency bands of rock samples under different stress paths are listed in Table 2. The width of low-frequency and high-frequency band of FT1-3 specimen is larger than that of NF1. Moreover, the frequency of FT1-3 is higher than that of NF1. The width and frequency of each frequency band of FT2 specimen are roughly the same as those of NF2, and the width of the low-frequency band of FT2 specimen is slightly larger than that of NF2. The width of the low-frequency band and high-frequency band of FT3 specimen is larger than that of NF3 corresponding frequency band, and the frequency of each frequency band of FT3 specimen is roughly the same as that of NF3. The width of the lowfrequency band and high-frequency band of FT4 specimen is larger than that of corresponding frequency band of NF4, and the frequency of the high-frequency band of FT4 specimen is greater than that of the high-frequency band of NF4. Generally speaking, the width of the low-frequency band of rock sample subjected to F-T cycles is larger than that of the rock sample under the natural state, and the frequency and width of the high-frequency band are larger than those of the high-frequency band under the natural state. The AE frequency is inversely proportional to the crack size. Therefore, the large-scale and small-scale cracks produced by F-T tuff samples are more than those of unfrozen 


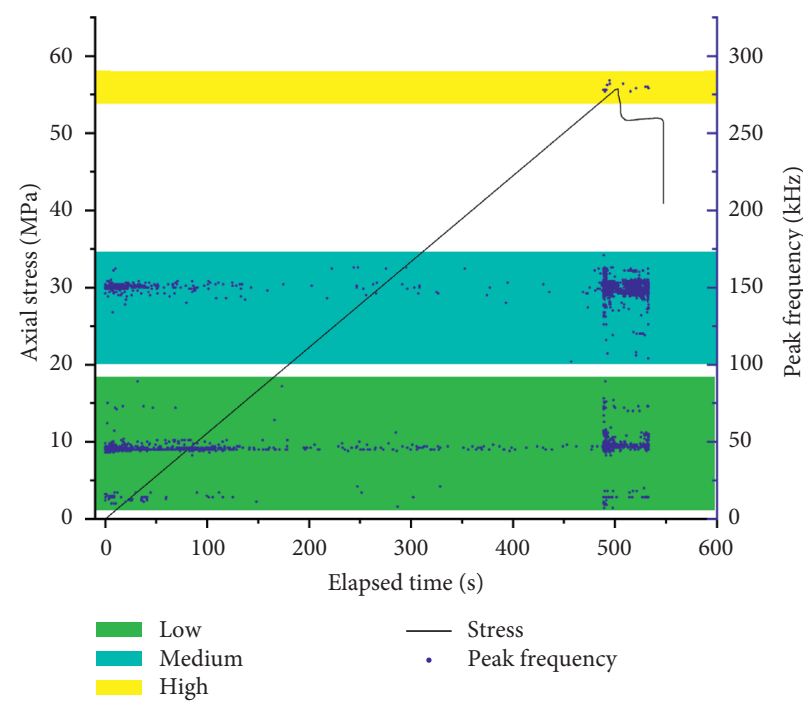

(a)

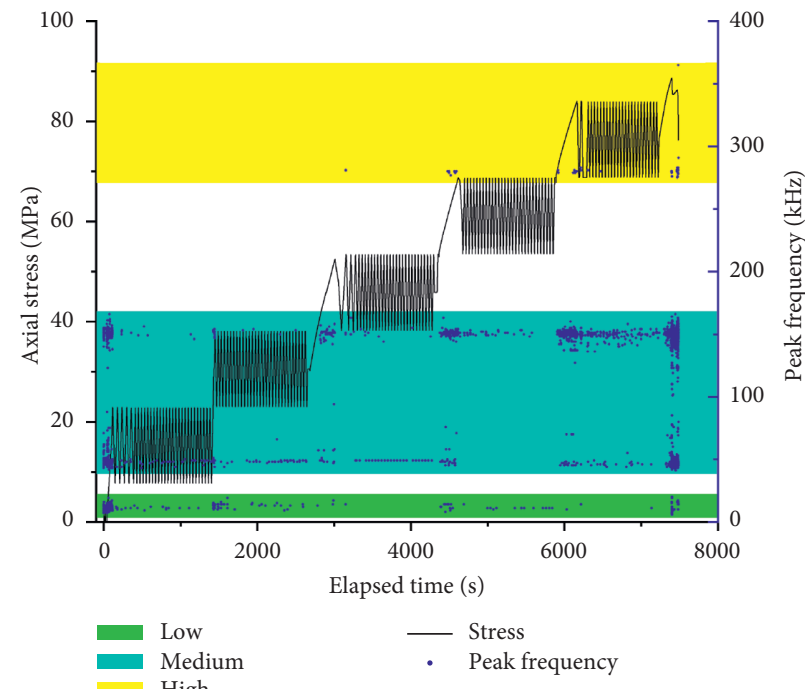

(c)

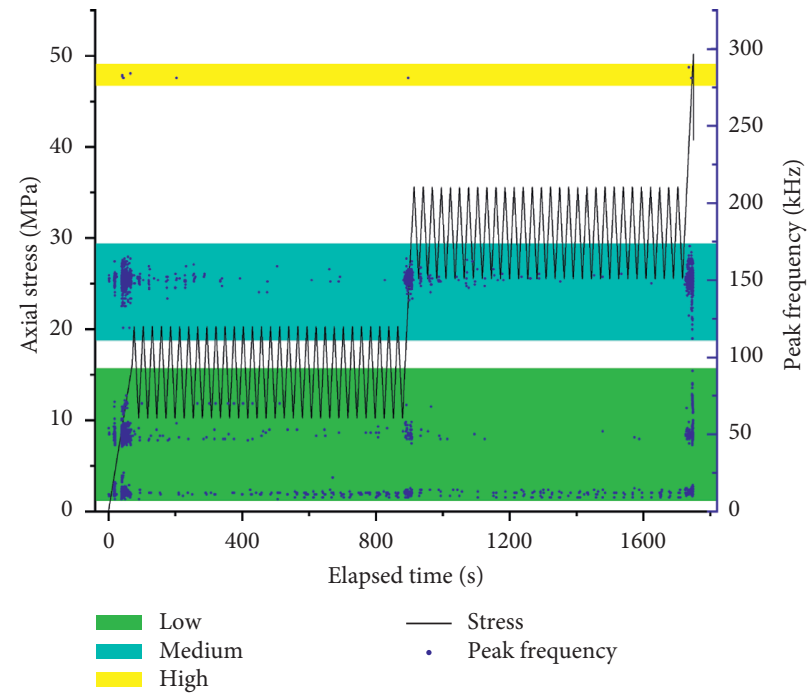

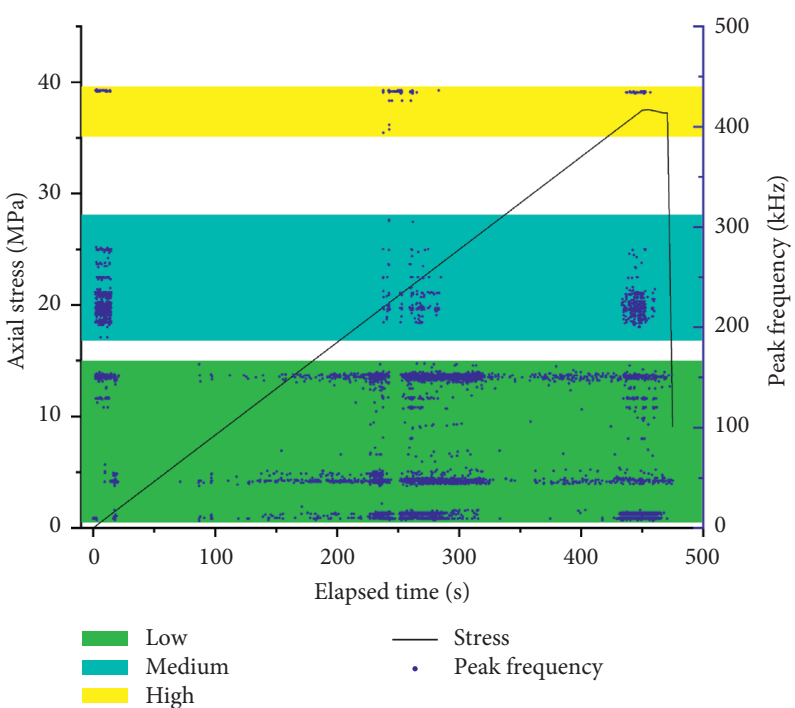

(b)

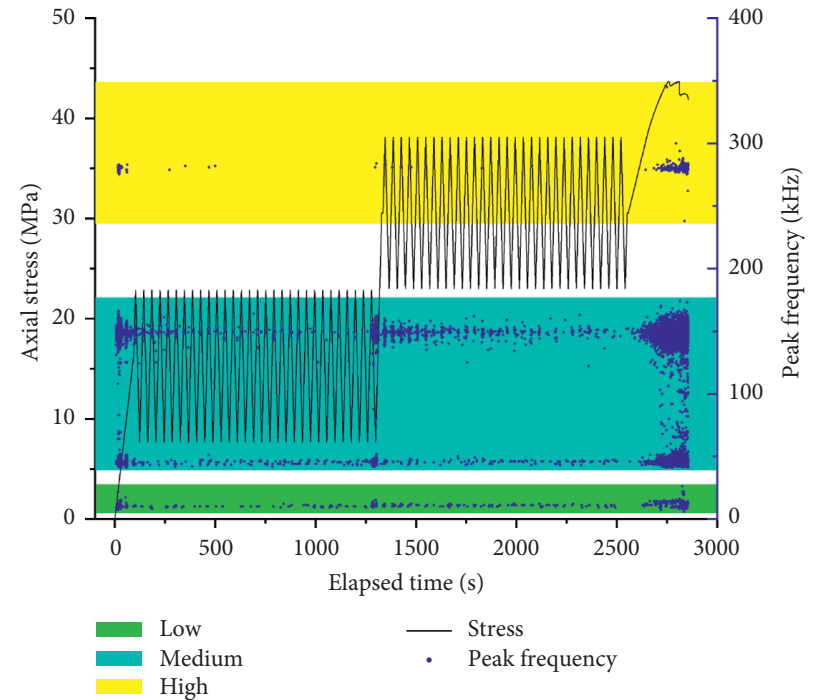

(d)

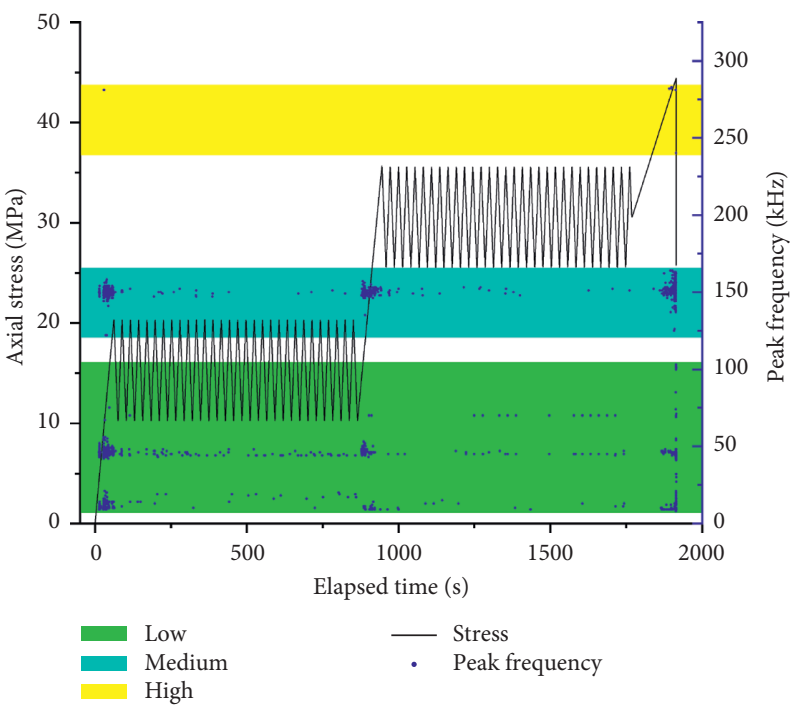

(f)

Figure 12: Continued. 


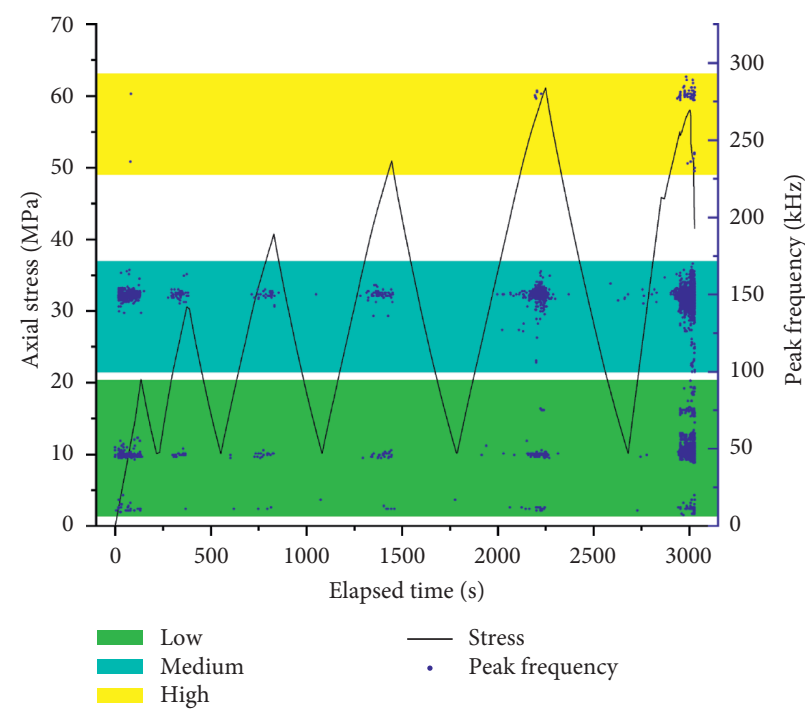

(g)

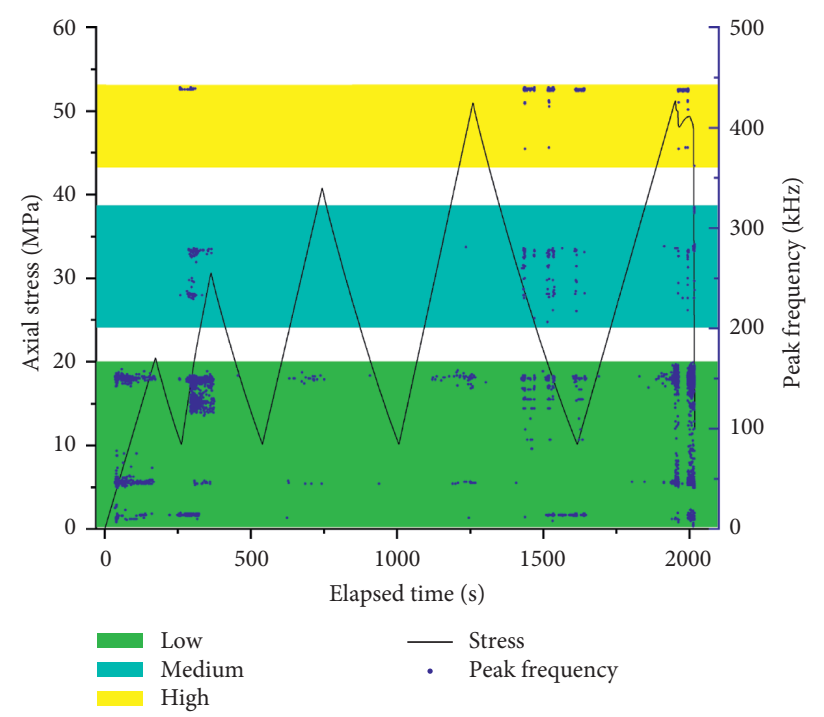

(h)

FIGURE 12: AE peak frequency with time curves of tuff specimens under different stress paths: (a) NF1; (b) FT1-3; (c) NF2; (d) FT2; (e) NF3; (f) FT3; (g) NF4; (h) FT4.

TABle 2: Frequency band width of AE of tuff samples under different stress paths.

\begin{tabular}{lccr}
\hline Sample ID & Low frequency $(\mathrm{kHz})$ & Medium frequency $(\mathrm{kHz})$ & High frequency $(\mathrm{kHz})$ \\
\hline NF1 & {$[0,90]$} & {$[100,170]$} & {$[270,290]$} \\
FT1-3 & {$[0,165]$} & {$[185,310]$} & {$[390,440]$} \\
NF2 & {$[0,20]$} & {$[40,165]$} & {$[270,365]$} \\
FT2 & {$[0,30]$} & {$[40,175]$} & {$[235,345]$} \\
NF3 & {$[0,90]$} & {$[110,175]$} & {$[275,290]$} \\
FT3 & {$[0,105]$} & {$[120,165]$} & {$[240,285]$} \\
NF4 & {$[0,95]$} & {$[100,170]$} & {$[230,290]$} \\
FT4 & {$[0,165]$} & {$[200,320]$} & {$[360,440]$} \\
\hline
\end{tabular}

samples. The peak frequency of AE can also be proved by the results of $\mathrm{AE}$ count rate and energy analysis on $\mathrm{AE}$ activity.

3.6. Failure Characteristic Analysis. The failure modes of tuff samples under different stress paths are shown in Figure 13. Each sample was photographed from the front and back directions, and the red circle in the figure indicates the position of the falling block after the test. After the F-T cycles, the failure modes of the specimens are obviously different, and the different failure modes indicate different failure modes. NF1, NF2, NF3, and NF4 specimens did not undergo F-T cycles, and their structures remained intact. Some longitudinal microcracks appeared in NF1 specimen. Under the action of axial compressive stress, Poisson effect results in obvious longitudinal cracks, and the failure mode is tensile failure. NF2, NF3, and NF4 specimens show obvious oblique shear failure characteristics under uniaxial compression. The specimens of FT1-3, FT2, FT3, and FT4 experienced $30 \mathrm{~F}-\mathrm{T}$ cycles. The original rock microstructure was damaged to a certain extent, and the fabric changes and the structure were incomplete. Some longitudinal microcracks appear in FT1-3 specimen, and some fragments fly out under the action of axial compressive stress. The Poisson effect makes the specimen appear obvious longitudinal through main crack, which is a typical tensile failure mode. There are many obvious longitudinal cracks in FT2 specimen, which are tensile failure. After the compression test, larger test blocks fly out of the FT3 specimen. There is block falling at the beginning and end of inclined fracture. There are both inclined and longitudinal cracks, which are tensile and shear failure. There are no vertical cracks or inclined cracks in FT4 specimen, which is local splitting failure. Generally speaking, there are both primary and secondary fractures in the fracture after failure, and there are local blocks falling at the initial position of the fracture. Freezethaw rock samples show more irregular failure forms than unfrozen rock samples.

\section{Discussion}

Although a large number of studies have been carried out on the influence of F-T cycles on the mechanical properties of rocks, most of them studied the macrofracture behavior of rocks by analyzing the stress-strain response and ultimate failure morphology of rocks. Especially, the acoustic 


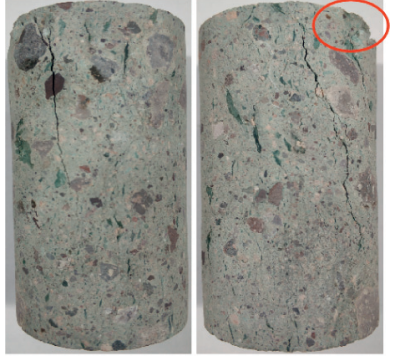

(a)

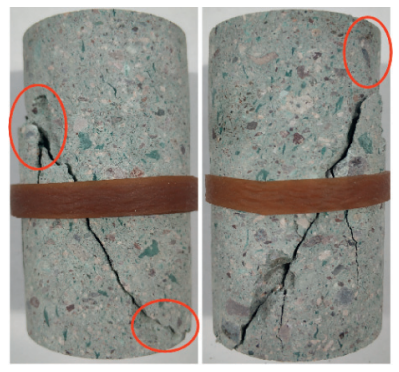

(e)

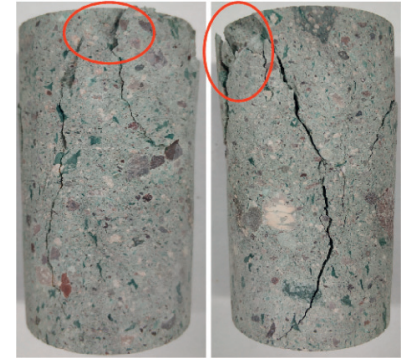

(b)

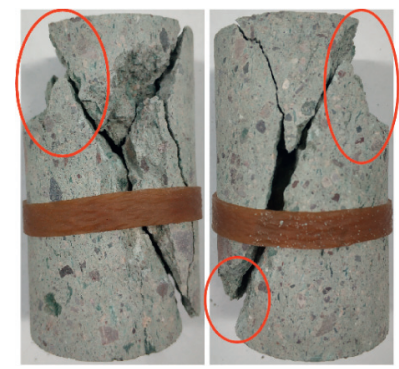

(f)

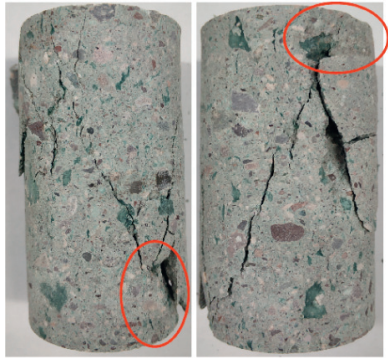

(c)

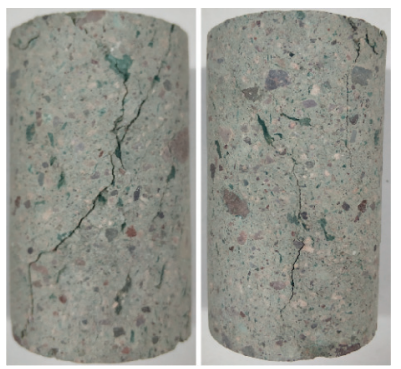

(g)

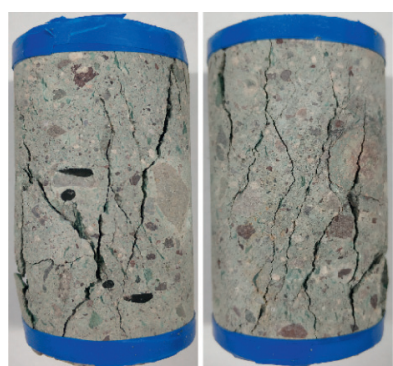

(d)

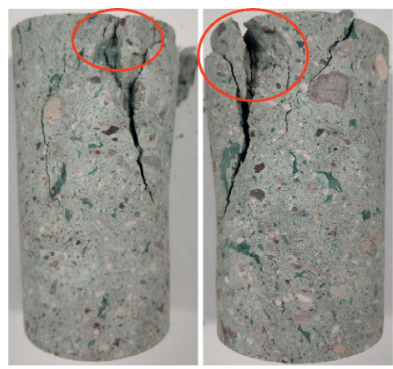

(h)

FIGURE 13: Failure samples of tuff after different stress path tests: (a) NF1; (b) FT1-3; (c) NF2; (d) FT2; (e) NF3; (f) FT3; (g) NF4; (h) FT4.

properties of F-T rock under different stress paths were not studied deeply. In this paper, we studied the mechanical and AE characteristics of tuff samples treated with different times of F-T under four different stress paths. Firstly, F-T tests were carried out on tuff samples, and then $\mathrm{AE}$ was used to monitor the failure process of rock samples during the uniaxial compression test. The strength, deformation, and fracture behavior of tuff were systematically studied by means of $\mathrm{AE}$ counting, $\mathrm{AE}$ energy, frequency spectrum characteristics, and failure mode analysis. Our experimental data showed that the AE characteristics of F-T tuff were different under different stress paths.

Compared with the rock without F-T cycles, there were a lot of pores and microcracks in the rock after F-T cycles, and the internal structure of rock was deteriorated due to defects. Therefore, the accompanying energy release rate was relatively low, and the AE count/energy (or cumulative number) was lower than that of the undamaged rock. The analysis of $\mathrm{AE}$ event parameters revealed the progressive failure process of rock, and its AE curve was affected by F-T cycles. Except for NF2 and FT2 specimens, the peak strength of F-T specimens was $9 \%-33 \%$ lower than that of unfrozen samples. The peak strain of unfrozen rock sample was $0.30 \%$ $0.34 \%$, and that of frozen thawed rock sample was $0.29 \%$ $0.32 \%$. Compared with NF2, the peak stress and strain of FT2 varied greatly. The peak strength of FT2 was 52\% lower than that of NF2, and the peak strain of FT2 was 37\% lower than that of NF2. This was mainly related to the microstructure of tuff, which made the rock samples have certain differences. According to the deformation characteristics of cyclic loading and unloading, the deformation mainly occurred in the stage of stress increase, and the strain changed little in the stage of fatigue loading. However, the volume strain of FT2 specimen changed greatly in the second fatigue loading stage, which decreased from $11.27 \%$ to $7.35 \%$. This indicated that the volume strain of tuff specimens after F-T cycles also changed greatly during the cyclic fatigue loading stage. From the plastic strain of NF4 and FT4, it can be seen that under the same loading conditions, the frozen thawed rock sample would produce greater plastic strain than the unfrozen rock sample. The energy analysis results showed that the AE energy curve jumps in the stress increasing stage, but the stress corresponding to the jumping time did not always increase. The jump time was not only related to the initiation of new cracks but also to the existing fractures produced by F-T cycles. The test results further revealed the frequency spectrum characteristics of rock; there were more large-scale and small-scale cracks in the frozen and thawed tuff samples than in the unfrozen samples. In terms of failure mode, tensile and shear failure occurred mainly in tuff samples. The number of cracks in frozen thawed samples was more than that in unfrozen samples, and the scale was larger.

The samples of FT1-3, FT2, FT3, and FT4 underwent 30 F-T cycles. Compared with the test results of different stress paths of these rock samples, the peak stress and peak strain had little change. According to the AE count of the four rock samples, most of the sudden changes occurred in the stress increasing stage and the most obvious at the failure time. However, under the condition of equal incremental cyclic loading and unloading, sudden change may occur in the unloading stage, which indicated that a large new fracture will also occur in the unloading stage. According to the $\mathrm{AE}$ energy of the four rock samples, the elastic strain energy stored at the time of failure suddenly released, and the $\mathrm{AE}$ energy increases suddenly, and the energy release rate was the highest at the failure time. However, for FT1-3 specimen, local failure occurred during the loading process, and the release of elastic strain energy increased suddenly, and the 
released energy was more than that after the peak strength. This was mainly because the interaction between the existing F-T damage cracks and the newly excited cracks changes the rock structure and affects the energy release. From the perspective of energy evolution, the nonlinear mechanical behavior and physical mechanism of rock deformation can be studied essentially. In order to reveal the effect of F-T treatment on the failure mechanism, the characteristics of AE peak frequency of rock samples were analyzed, and the macroscopic failure modes were described. The test results showed that the crack size and density of the failure specimen are consistent with the results of AE spectrum analysis.

\section{Conclusion}

The purpose of this study was to investigate the effects of F-T cycles on geomechanical and acoustic properties of tuff specimens under different stress paths. The samples were processed by artificial F-T cycles to simulate the field environment. The experimental results reveal the influence of F-T fatigue damage on strength, deformation, ultrasonic velocity, AE count, energy, and frequency spectrum characteristics. The following conclusions can be drawn from this study:

(1) The F-T coefficient of tuff specimens decreased with the increase in F-T cycles; the mass loss rate and the loss rate of $\mathrm{P}$-wave velocity increased with the increase in F-T cycles.

(2) Under the same stress path, the cumulative AE count/energy of rock samples subjected to F-T cycles was less than that of rock samples not subjected to F-T cycles. The width of low-frequency band of rock samples after F-T cycle was larger than that of rock samples in the natural state. Moreover, the frequency and width of the high-frequency band were larger than those of the rock samples in the natural state.

(3) There were both primary and secondary cracks in the fracture after failure, and there was local block falling at the initial position of the fracture. The rock samples after F-T cycles presented more irregular failure modes than those of samples without F-T cycles. The energy used to drive crack propagation is less than that of samples without F-T cycles.

(4) The peak stress and peak strain of F-T rock samples varied little under different stress paths, but the acoustic emission characteristics were obviously different. The results of $\mathrm{AE}$ parameter analysis, frequency spectrum analysis, and failure mode description were basically consistent. The research results can provide a certain basis for the slope stability research of Beizhan mine in Hejing county.

\section{Data Availability}

The data used to support the findings of this study are included within the article.

\section{Conflicts of Interest}

The authors declare that they have no conflicts of interest regarding the publication of this paper.

\section{Acknowledgments}

This study was financially supported by the National Key R\&D Program of China (grant no. 2018YFC0808402).

\section{References}

[1] M. Takarli, W. Prince, and R. Siddique, "Damage in granite under heating/cooling cycles and water freeze-thaw condition," International Journal of Rock Mechanics and Mining Sciences, vol. 45, no. 7, pp. 1164-1175, 2008.

[2] X. Tan, W. Chen, J. Yang, and J. Cao, "Laboratory investigations on the mechanical properties degradation of granite under freeze-thaw cycles," Cold Regions Science and Technology, vol. 68, no. 3, pp. 130-138, 2011.

[3] Y. Zhang, Y. Jiang, D. Asahina, and C. Wang, "Experimental and numerical investigation on shear failure behavior of rocklike samples containing multiple non-persistent joints," Rock Mechanics and Rock Engineering, vol. 53, no. 10, pp. 47174744, 2020.

[4] M. Bost and A. Pouya, "Stress generated by the freeze-thaw process in open cracks of rock walls: empirical model for tight limestone," Bulletin of Engineering Geology and the Environment, vol. 76, no. 4, pp. 1491-1505, 2017.

[5] M. Seto, "Freeze-thaw cycles on rock surfaces below the timberline in a montane zone: field measurements in Kobugahara, Northern Ashio Mountains, Central Japan," Catena, vol. 82, no. 3, pp. 218-226, 2010.

[6] F. Bayram, "Predicting mechanical strength loss of natural stones after freeze-thaw in cold regions," Cold Regions Science and Technology, vol. 83-84, pp. 98-102, 2012.

[7] A. Jamshidi, M. R. Nikudel, and M. Khamehchiyan, "Predicting the long-term durability of building stones against freeze-thaw using a decay function model," Cold Regions Science and Technology, vol. 92, pp. 29-36, 2013.

[8] J. Park, C.-U. Hyun, and H.-D. Park, "Changes in microstructure and physical properties of rocks caused by artificial freeze-thaw action," Bulletin of Engineering Geology and the Environment, vol. 74, no. 2, pp. 555-565, 2014.

[9] T. C. Chen, M. R. Yeung, and N. Mori, "Effect of water saturation on deterioration of welded tuff due to freeze-thaw action," Cold Regions Science and Technology, vol. 38, no. 2-3, pp. 127-136, 2004.

[10] B. Ke, K. Zhou, C. Xu, H. Deng, J. Li, and F. Bin, "Dynamic mechanical property deterioration model of sandstone caused by freeze-thaw weathering," Rock Mechanics and Rock Engineering, vol. 51, no. 9, pp. 2791-2804, 2018.

[11] H. C. Zhao, X. L. Zhang, G. Han, and H. Chen, "Experimental investigation on the physical and mechanical properties deterioration of oil shale subjected to freeze-thaw cycles," Arabian Journal of Geosciences, vol. 12, no. 16, 2019.

[12] İ. İnce and M. Fener, "A prediction model for uniaxial compressive strength of deteriorated pyroclastic rocks due to freeze-thaw cycle," Journal of African Earth Sciences, vol. 120, pp. 134-140, 2016.

[13] H. Jia, W. Xiang, and M. Krautblatter, "Quantifying rock fatigue and decreasing compressive and tensile strength after repeated freeze-thaw cycles," Permafrost and Periglacial Processes, vol. 26, no. 4, pp. 368-377, 2015. 
[14] T. Han, J. Shi, and X. Cao, "Fracturing and damage to sandstone under coupling effects of chemical corrosion and freeze-thaw cycles," Rock Mechanics and Rock Engineering, vol. 49, no. 11, pp. 4245-4255, 2016.

[15] Y. Chen, P. Wu, Q. Yu, and G. Xu, "Effects of freezing and thawing cycle on mechanical properties and stability of soft rock slope," Advances in Materials Science and Engineering, vol. 2017, Article ID 3173659, 10 pages, 2017.

[16] X. Luo, N. Jiang, C. Zuo, Z. Dai, and S. Yan, "Damage characteristics of altered and unaltered diabases subjected to extremely cold freeze-thaw cycles," Rock Mechanics and Rock Engineering, vol. 47, no. 6, pp. 1997-2004, 2014.

[17] M. H. Ghobadi and R. Babazadeh, "Experimental studies on the effects of cyclic freezing-thawing, salt crystallization, and thermal shock on the physical and mechanical characteristics of selected sandstones," Rock Mechanics and Rock Engineering, vol. 48, no. 3, pp. 1001-1016, 2015.

[18] X. Fang, J. Xu, and P. Wang, "Compressive failure characteristics of yellow sandstone subjected to the coupling effects of chemical corrosion and repeated freezing and thawing," Engineering Geology, vol. 233, pp. 160-171, 2018.

[19] T. De Kock, M. A. Boone, T. De Schryver et al., "A pore-scale study of fracture dynamics in rock using X-ray micro-CT under ambient freeze-thaw cycling," Environmental Science \& Technology, vol. 49, no. 5, pp. 2867-2874, 2015.

[20] Y. Wang, W. K. Feng, H. J. Wang, C. H. Li, and Z. Q. Hou, "Rock bridge fracturing characteristics in granite induced by freeze-thaw and uniaxial deformation revealed by $\mathrm{AE}$ monitoring and post-test CT scanning," Cold Regions Science and Technology, vol. 177, 2020.

[21] Y. Wang, J. Q. Han, and C. H. Li, “Acoustic emission and CT investigation on fracture evolution of granite containing two flaws subjected to freeze-thaw and cyclic uniaxial increasingamplitude loading conditions," Construction and Building Materials, vol. 260, 2020.

[22] Y. Wang, W. Feng, H. Wang, J. Han, and C. Li, "Geomechanical and acoustic properties of intact granite subjected to freeze-thaw cycles during water-ice phase transformation in beizhan's open pit mine slope, Xinjiang, China," Water, vol. 11, no. 11, 2019.

[23] K.-P. Zhou, B. Li, J.-L. Li, H.-W. Deng, and F. Bin, "Microscopic damage and dynamic mechanical properties of rock under freeze-thaw environment," Transactions of Nonferrous Metals Society of China, vol. 25, no. 4, pp. 1254-1261, 2015.

[24] C. Zhai, S. Wu, S. Liu, L. Qin, and J. Xu, "Experimental study on coal pore structure deterioration under freeze-thaw cycles," Environmental Earth Sciences, vol. 76, no. 15, 2017.

[25] X. Ni, X. Shen, and Z. Zhu, "Mechanical and acoustic emission characteristics of sandstone through triaxial unloading test after cyclic freezing-thawing treatment," Advances in Civil Engineering, vol. 2020, Article ID 7150536, 12 pages, 2020.

[26] L. Chen, P. Wu, Y. Chen, and W. Zhang, "Experimental study on physical-mechanical properties and fracture behaviors of saturated yellow sandstone considering coupling effect of freeze-thaw and specimen inclination," Sustainability, vol. 12, no. 3, 2020.

[27] B. Liu, Y. Ma, G. Zhang, and W. Xu, "Acoustic emission investigation of hydraulic and mechanical characteristics of muddy sandstone experienced one freeze-thaw cycle," Cold Regions Science and Technology, vol. 151, pp. 335-344, 2018.

[28] D. Amitrano, S. Gruber, and L. Girard, "Evidence of frostcracking inferred from acoustic emissions in a high-alpine rock-wall," Earth and Planetary Science Letters, vol. 341-344, pp. 86-93, 2012.

[29] T. Yin, Q. Li, and X. Li, "Experimental investigation on mode I fracture characteristics of granite after cyclic heating and cooling treatments," Engineering Fracture Mechanics, vol. 222, 2019.

[30] Q. Liu, Z. Qian, and Z. Wu, "Micro/macro physical and mechanical variation of red sandstone subjected to cyclic heating and cooling: an experimental study," Bulletin of Engineering Geology and the Environment, vol. 78, no. 3, pp. 1485-1499, 2019.

[31] Y. Wang, C. H. Li, H. Liu, and J. Q. Han, "Fracture failure analysis of freeze-thawed granite containing natural fracture under uniaxial multi-level cyclic loads," Theoretical and Applied Fracture Mechanics, vol. 110, 2020.

[32] Y. Zhao, S. Gong, T. Teng, Y. Jiang, Z. Yang, and K. Chen, "Characteristics of the load/unload response ratio of raw coal under uniaxial multi-level cyclic loading," Chinese Journal of Rock Mechanics and Engineering, vol. 37, no. 5, pp. 1096-1105, 2018.

[33] D. Li, Z. Sun, X. Li, and T. Xie, "Mechanical response and failure characteristics of granite under different stress paths in triaxial loading and unloading conditions," Chinese Journal of Rock Mechanics and Engineering, vol. 35, pp. 3449-3457, 2016.

[34] Y. Wang, C. H. Li, and Y. Z. Hu, "Experimental investigation on the fracture behaviour of black shale by acoustic emission monitoring and CT image analysis during uniaxial compression," Geophysical Journal International, vol. 213, no. 1, pp. 660-675, 2018.

[35] Y. Wang, W. K. Feng, and C. H. Li, "On anisotropic fracture and energy evolution of marble subjected to triaxial fatigue cyclic-confining pressure unloading conditions," International Journal of Fatigue, vol. 134, 2020.

[36] Y. Wang, S. Gao, D. Liu, and C. Li, "Anisotropic fatigue behaviour of interbeded marble subjected to uniaxial cyclic compressive loads," Fatigue \& Fracture of Engineering Materials \& Structures, vol. 43, no. 6, pp. 1170-1183, 2020.

[37] Y. Wang, C. Li, J. Han, and H. Wang, "Mechanical behaviours of granite containing two flaws under uniaxial increasingamplitude fatigue loading conditions: an insight into fracture evolution analyses," Fatigue \& Fracture of Engineering $\mathrm{Ma}$ terials \& Structures, vol. 43, no. 9, pp. 2055-2070, 2020.

[38] Y. Wang, W. K. Feng, R. L. Hu, and C. H. Li, "Fracture evolution and energy characteristics during marble failure under triaxial fatigue cyclic and confining pressure unloading (FC-CPU) conditions," Rock Mechanics and Rock Engineering, vol. 53, 2020.

[39] W. Yu, D. Liu, J. Han, C. Li, and L. Hao, "Effect of fatigue loading-confining stress unloading rate on marble mechanical behaviors: an insight into fracture evolution analyses," Journal of Rock Mechanics \& Geotechnical Engineering, vol. 12, 2020.

[40] Y. Wang, S. H. Gao, C. H. Li, and J. Q. Han, "Investigation on fracture behaviors and damage evolution modeling of freezethawed marble subjected to increasing- amplitude cyclic loads," Theoretical and Applied Fracture Mechanics, vol. 109, Article ID 102679, 2020.

[41] M. C. He, J. L. Miao, and J. L. Feng, "Rock burst process of limestone and its acoustic emission characteristics under truetriaxial unloading conditions," International Journal of Rock Mechanics and Mining Sciences, vol. 47, no. 2, pp. 286-298, 2010.

[42] Z. Wang, J. Ning, and H. Ren, "Frequency characteristics of the released stress wave by propagating cracks in brittle materials," Theoretical and Applied Fracture Mechanics, vol. 96, pp. 72-82, 2018. 